\title{
The economic growth enigma revisited: The EU-15 since the 1970s
}

\author{
Vlasios Voudouris ${ }^{\mathrm{b}, 1}$, Robert Ayres ${ }^{\mathrm{a}}$, Andre Cabrera Serrenho ${ }^{\mathrm{c}}$, Daniil \\ Kiose $^{\mathrm{d}}$ \\ ${ }^{a}$ INSEAD, 77305 Fountainebleau, France \\ ${ }^{b}$ ESCP Europe Business School, 527 Finchley Road, London, NW3 7BG, UK \\ ${ }^{c}$ University of Cambridge, Trumpington Street, Cambridge, CB2 1PZ, UK \\ ${ }^{d}$ School of Economics, Politics and History, Kingston University, Kingston upon \\ Thames, Surrey, KT1 2EE, UK
}

\begin{abstract}
Current macro-econometric models mostly incorporate just two factors of production, labor and capital (with a time-dependent multiplier representing technological change or total factor productivity). These models assume that energy is an intermediate product of some combination of human labor and capital. These models also assume that the supply of energy is driven by economic demand. We assume the contrary, i.e. that useful energy is a primary input, derived (mostly) from natural capital. This failure to capture the impact of primary resources (as useful energy) on economic growth leads to inappropriate formulation of economic growth theories. To understand that impact better we need explicit evidence of marginal products of capital, labor and useful energy or useful work. As applied to the explanation of the past half century of economic growth of the EU-15 countries, the new results demonstrate the use of non-parametric relationships between capital, labor and useful energy to explain economic growth. They also indicate that marginal products of capital, labor and useful energy are variable the marginal product depends on the levels of capital stock, labor input and useful energy flows. The proposed semi-parametric production function suggests country-specific policy implications for the EU (and other countries).
\end{abstract}

Keywords: european economic growth, generalised production function, non-linear marginal products, useful energy

\footnotetext{
${ }^{1}$ vvoudouris@escpeurope.eu
} 


\section{Introduction}

It is too often forgotten that economic growth has been a relatively episodic phenomenon in human history. Modest periods of real growth have occurred at various times in the more distant past, but growth that took a century in the late middle ages is now sometimes compressed into a decade, or even a single year. What has changed?

Ultimately, the debate about future of economic growth is an empirical one, and resolving the debate requires examining fundamental structural parameters of the economy. One key question is: How big are the marginal products of capital, labor and useful energy?

We estimate a semi-parametric production function econometrically using a unique dataset. We then analyze the properties of the production function in order to understand the dynamic behavior of the three factors of production (capital, labor and useful energy) and of overall economic growth in the EU15 countries since the 1970s.

The key motivation of the work presented here is to enable the formulation of economic growth theories that fit the historical facts. Methodologically, the work presented here is consistent with Haavelmos Probability Approach in Economics (Haavelmo, 1944) in the sense of constituting a probabilistic formulation of economic theory using the generalized production function of Equation 2. Standard macroeconomic analysis then assumes the 'correct' economic model and then uses econometrics merely to estimate its parameters from the best available data.

In contrast to this prevailing orthodoxy, we formulate the growth model as a probabilistic production function, but we allow the form of the function to be estimated from data without assuming any particular parametric form. To quote Haavelmo (1989): "The basis of econometrics, the economic theories that we had been led to believe in by our forefathers, were perhaps not good enough. It is quite obvious that if the theories we build to simulate actual economic life are not sufficiently realistic, that is, if the data we get to work on in practice are not produced the way that economic theories suggest, then it is rather meaningless to confront actual observations with relations that describe something else" (section 4, paragraph 2).

An important advantage of the proposed generalized production function is that it is sufficiently realistic (see section 3) to permit meaningful links 
between policy measures and actual growth outcomes.

The familiar Cobb-Douglas production function (of capital and labor) takes the following mathematical form:

$$
Y_{t}=A_{t} K_{t}^{\alpha} L_{t}^{\beta}
$$

where $Y_{t}$ is the GDP, $K_{t}$ is the stock of capital and $L_{t}$ is the stock of labor, while parameters $\alpha$ and $\beta$ are constants. Following Solow $(1956,1957), A_{t}$ has been interpreted as the effect of 'technical progress' (now called total factor productivity TFP). This multiplier presumably captures the unexplained fraction of total economic output that is not caused by capital and labour.

We take the view that useful energy is an important factor of production. We reject the standard assumption that the output elasticity of each factor must be equal to the cost share of that factor in the GDP (Kümmel et al., 2010). We also reject the usual assumption that the functional relationship between GDP and capital, labor and useful energy is (log) linear (as is the case with the Cobb-Douglas production function). Instead, we explore empirically whether the marginal products of capital, labor and useful energy are constant, or not. If they are not constant, important policy implications can follow.

The rest of the paper is organized as follows. Section 2 provides a discussion of the key concepts of capital, labor and useful energy. This is following by the mathematical description of the proposed generalized production func-

tion. Section 4 presents the unique dataset for the EU15 countries used in this study. It also explains how useful energy consumption is estimated. It also presents the historical evolution of the useful energy categories: mechanical work, light, heat, muscle work and other electrical uses. 5 presents the key insights of the estimated production function of the EU15 countries. Concluding remarks and key policy implications are given in 6 .

\section{Key concepts: Capital, labour and useful energy}

How can we account for capital? The so-called Cambridge controversies in the 1960s highlighted key problems, notably the difficulty of aggregating heterogeneous capital comprising machines, buildings, inventories, infrastructure, money and even natural resource stocks (Harcourt, 1972). In practice, we adopt Maddisons perpetual inventory method (PIM) to measure capital in monetary terms, accumulating capital from new investment less depreciation (Maddison, 1982). 
Another issue is how to define and characterize factors of production. The classic view is that, if an input is essential, i.e. if there is no or very limited possibility of substitution by another input, then it must be treated as a factor of production e.g. Nordhaus (1992). In this paper we start from the fact that useful energy, in the thermodynamic sense, is essential to all productive activities. Capital equipment, without a source of driving power, is inert and unproductive. The same is true of human (or animal) labor. Virtually all types of capital equipment are involved in doing useful work.

Not all energy is useful to us humans. The ocean contains a lot of energy as low temperature heat, but not all energy can do work and most of it is not useful or potentially useful. The component of energy that can perform work is called exergy. From a technical thermodynamic perspective, work means exerting force against some kind of resistance. It may be lifting a weight, winding a spring, or propelling a projectile. But not all work is useful. The eruption of volcanoes, the rise and erosion of the mountains and the carving of valleys are examples of work done by natural forces.

In other words, total energy includes a component that is non-useful and that often lost as waste heat. On the one hand, one can argue that overall economic behavior is affected (negatively) by this component and that, therefore, it should not be neglected in production theory. However, we argue that the non-useful (waste) component of energy should be considered separately as a form of pollution, because, in principle, the harmful component of energy can, and should, be subject to regulation and ameliorated by counter-measures. More pertinent, the product of energy times first law efficiency equals work, which is also the product of exergy times second law efficiency

For our purposes the exergy consumed by human activities is assumed to be useful, insofar as it drives economic growth. Much the same point can be made about work. To avoid confusion, we adapt the term "useful energy" to account for energy that does work that yields goods and services to be consumed by ourselves or our agents.

Since passive capital produces nothing, it is a short step to realize that all economic production is really comprised of products made from materials transformed by useful energy, plus services to humans generated by those products. (This is even true of information production, processing and transmission, with the exception of mental work done by humans without computational tools or word-processing assistance.) Hence useful energy is essential to every economic activity, just as capital (in some form) and labor 
(in some form) are also essential. Thus useful energy (exergy) must be regarded as a factor of production in the economic sense, along with traditional capital and labor.

The three driving variables and especially capital and useful energy are also to some extent complements. Machines need workers to operate and maintain them, and they need useful energy to do work. Given that total energy is the sum of useful and non-useful components, denoted exergy and anergy, respectively, and that anergy includes waste heat and by extension other wastes and pollutants, it can be argued that anergy should be accounted for explicitly in the production function. This might be a worthwhile future direction for research. However, we do not pursue it further in this paper.

Potential output (GDP) is typically expressed as a linear homogeneous function of two independent inputs, namely capital services and labor services. Our approach, discussed in the next section, allows for more complex relationships.

\section{The Generalised (semi-parametric) Production Function}

Our generalized semi-parametric production function should not be understood as a tool for making point-estimates, or deterministic forecasts, as standard parametric (linear or non-linear) production functions are typically used. When (or if) one has prior knowledge of the parametric relationships between the GDP and the factors of production, then it is possible to use non-linear parametric models. However, when, or if, those relationships are not known in advance, our non-parametric approach offers an alternative. It can be regarded as a tool for estimating the probability density of economic growth along a given path, analogous to a wave-function in quantum mechanics. The future probabilities are calculated from all of the information embodied in past growth trajectories. Moreover, it uses a non-parametric method (not to be confused with non-linear parametric models) in order to capture the diversity of the EU-15 countries.

Following Ayres and Voudouris (2014), we start with a general model of an economy that is an extension of the standard neoclassical growth model. It has one output $Y$ and multiple inputs. The $Y$ might be an index of true national income that corrects for certain disamenities (e.g. the costs of ameliorating pollution). Thus, the $Y$ might be a compressed indicator (or function) of more than one output. In our case, the $Y$ is the Gross Domestic 
Product (GDP) without correcting for any disamenities. For simplicity, we omit the time sub-scripts $t$ where inessential.

We specify a generalized production function (for EU economies) that attempts to account for the stylized features of the data. Our proposed production function assumes three factors of production, namely capital, labor and useful exergy. Because we want to estimate marginal products of capital, labor and useful exergy, we take natural logarithms of the data. The $\log$ of capital $K$ is $k$, the $\log$ of labor $L$ is $l$, the $\log$ of useful exergy $E$ is $e$ and the $\log$ of $\operatorname{GDP}(Y)$ is $y$.

Instead of assuming a functional form with three parameters corresponding to the three variables (factors), our production function is defined by (three) parameters describing the distribution of errors or departures from the most probable trajectory. The distribution parameters reflect different aspects of the dynamics of $y$. In particular, we use the $T F(\mu, \sigma, \nu)$ distribution, which is the so-called $t$-family of distributions (Johnson et al., 1995). The three distribution parameters of the $T F(\mu, \sigma, \nu)$ distribution are as follows:

- $\mu$ : the expected value (or mean) of $y$

- $\sigma$ : the standard deviation around the expected value of $y$

- $\nu$ : the kurtosis (measure of the heaviness of the distribution tails) of $y$

We can specify a regression-type of model for any of the distribution parameters. This means that not only the $\mu$ distribution parameter but also the other distribution parameters can be modelled as additive functions of $k$, $l$ and $e$. In order to keep the model simple (we only have yearly observations), we provide a regression-type of model for the $\mu$ distribution parameter. The mathematical representation of the aggregate production function is then given by:

$$
\begin{array}{r}
y \sim T F(\mu, \sigma, \nu) \\
\mu=\alpha^{\mu}+f_{1}(l)+f_{2}(k)+f_{3}(e) \\
\log (\sigma)=\alpha^{\sigma} \\
\log (\nu)=\alpha^{\nu}
\end{array}
$$

were $\alpha$ represents the intercept (or global mean) and $f_{j}($.$) are smooth func-$ tions of the production factors. For a detailed discussion for the representation of the smooth functions $f_{j}($.$) (see Wood (2006)). For the algorithm to$ 
estimate the production function of Equation 2 see Rigby and Stasinopoulos (2005) and Voudouris et al. (2012). It is important to emphasize that the selection of the smoothing parameter of the function $f_{j}($.$) is not arbitrary.$ This is because it is estimated using a local maximum likelihood method. The model allows for rather flexible specification of $y$ on the predictors $k$, $l$ and $e$ by specifying the model only in terms of 'smooth functions' rather than detailed parametric relationships. The idea is that we estimate the form of $f_{j}($.$) from data without assuming that it has a particular simple$ mathematical form.

Appendix A provides further justification of the proposed (semi-parametric) production function [it is parametric because of the use of a parametric distribution and non-parametric because of the use of the non-parametric smooth $f($.$) ]. In brief we have chosen the t$ distribution based upon the model selection strategy described in a previous publication (Voudouris et.al. 2012). In effect, we have chosen the $t$ distribution from a large set of distributions (e.g., Gaussian, $t$-family, gamma distribution, skewed $t$ distribution, skew power exponential) based on goodness-of-fit. To be precise, we use the Generalised Akaike Information Criterion (GAIC) as a measure of goodness of fit of a model. The GAIC $(\mathrm{c})=-2 \times l+c \times e d f$, where $l$ is the log-likelihood function of the model and $e d f$ are the effective degrees of freedom of a fitted model (the dimension of the vector of model parameters). Ayres and Voudouris (2014) provide a detailed example of how to chose the distribution for the generalised production function.

Long-run growth depend upon the growth rates of the factors of production, the rate and direction of technological change, and the marginal products of capital, labor and useful energy. Thus, it is important to enhance our knowledge about all these factors in order to forecast whether the race between technological change/capital and natural capital (resource) scarcities will result in growth or stagnation. Effectively, the estimated trend in output provides a benchmark for assessment of economic performance and helps to determine the pace of sustainable growth on the basis of alternative assumptions about the longer-term growth determinants. Furthermore, it serves as a guide to comparative productivity analysis.

In the present circumstances of weakening of economic activity in the EU15 , the question of interest is whether we can expect substantially stronger economic growth in the coming years, or whether lower growth will prevail for an extended period of time. An empirical investigation of the trends of the growth determinants for the EU-15 countries is discussed below as a way of 
understanding the past and the present before structuring the uncertainties of the future.

\section{EU-15: Data and empirical developments}

It is hard to see how even the best of theoretical models could do more than frame the questions for empirical studies to address. Thus in the balance

of this study, we examine insights that we have gathered from exploring the history of economic growth of the EU15 countries.

\subsection{Data}

Useful energy (exergy) is presented in terajoules (TJ) and the estimation of useful energy is based upon the International Energy Agency energy balances (IEA, 2014). To estimate the useful energy, we used the following procedure (see Serrenho et al. (2014)):

- Energy is converted to exergy using Exergy $=\phi *$ Energy where $\phi$ is a conversion factor (see table 1).

- IEA energy balances provide systematic energy statistics for each EU15 country and year. Besides exhibiting a reasonable level of sectoral disaggregation, these energy balances provide final energy use data disaggregated in 63 different energy vectors that could be grouped in 9 sets with common exergy factors.

- The exergy values used in this paper for each year $t$ and country $c$ stand for final exergy consumption and were obtained from final energy data for each year, country, economic sector $i$, and energy vector $v$ as follows: $\operatorname{Exergy}_{t, c}=\sum_{i} \sum_{v} E_{i, v, t, c} * \phi_{v}$.

- Useful energy is the useful exergy of a given energy end use. It measures the result of an energy use rather than the amount of energy transferred to a final use. Formally, useful energy can be defined as the minimum amount of work (or exergy) required to produce a given energy transfer. Useful energy is obtained for each year $t$ and country $c$ summing the contribution of each combination of energy vector $v$ economic sector $i$ - energy end-use category $k$. This process requires the classification of each energy end-uses in one of the following categories: heat, mechanical drive, light, muscle work, and other 
electric uses. Useful work accounting also requires a mapping for energy end-uses and the estimation of second-law efficiencies, $e f_{t, c, k}$, for each end-use category . Useful energy $U E$ can then be obtained as: $U E_{t, c}=\sum_{k} \sum_{i} \sum_{v} E_{i, v, t, c} * \phi_{v} * e f_{t, c, k, v}$.

\begin{tabular}{cc}
\hline \hline Energy carriers & Conversion factor $\phi$ \\
\hline Coal products & 1.06 \\
Oil products & 1.06 \\
Coke & 1.05 \\
Natural gas & 1.04 \\
Combustible renewables & 1.11 \\
Electricity & 1.00 \\
Food and feed & 1.00 \\
CHP and geothermal heat & 0.40 \\
Solar thermal heat & 0.25 \\
\hline
\end{tabular}

Table 1: Considered exergy factors (Source: Chen and Chen (2007); Ertesvåg and Mielnik (2000); Wall et al. (1994)

The GDP time series were obtained from the AMECO database (AMECO, 2014). The values are in billion euros of the year 2005, using exchange rates. For Germany, the capital values until 1990 inclusive only include the states of the Federal Republic of Germany (West Germany). Labor is the total hours worked obtained from the Total Economy Database (Total Economy Database, 2014) and represents the yearly aggregate number of hours actually worked as an employee or as a self-employed person, when their output is within the production boundary. The values are presented in thousands of hours. For Germany, the labor values until 1969 inclusive only include the states of the Federal Republic of Germany (West Germany).

Capital is the net capital stock at constant prices for the total economy. This data was obtained from the AMECO database (AMECO, 2014) and calculated for each year $t$ as:

$$
O K N D_{t}=O K N D_{t-1}+\left(O I G T_{t}-\frac{U K C T_{t}}{P I G T_{t}} * 100\right)
$$

where $O K N D$ stands for the net capital stock at constant prices, OIGT for the gross fixed capital formation at constant prices, $U K C T$ for the consumption of fixed capital at current prices, and PIGT for the price deflator 
gross fixed capital formation. The values of this variable are presented in billion euros of the year 2005. For Germany, the capital values until 1990 inclusive only include the states of the Federal Republic of Germany (West Germany).

\subsection{Empirical developments}

Figure 1 shows the historic evolution of the index of GDP, capital, labor and useful energy of the EU15 countries. All graphics have the same scale to permit inter-country comparisons of the empirical developments. 

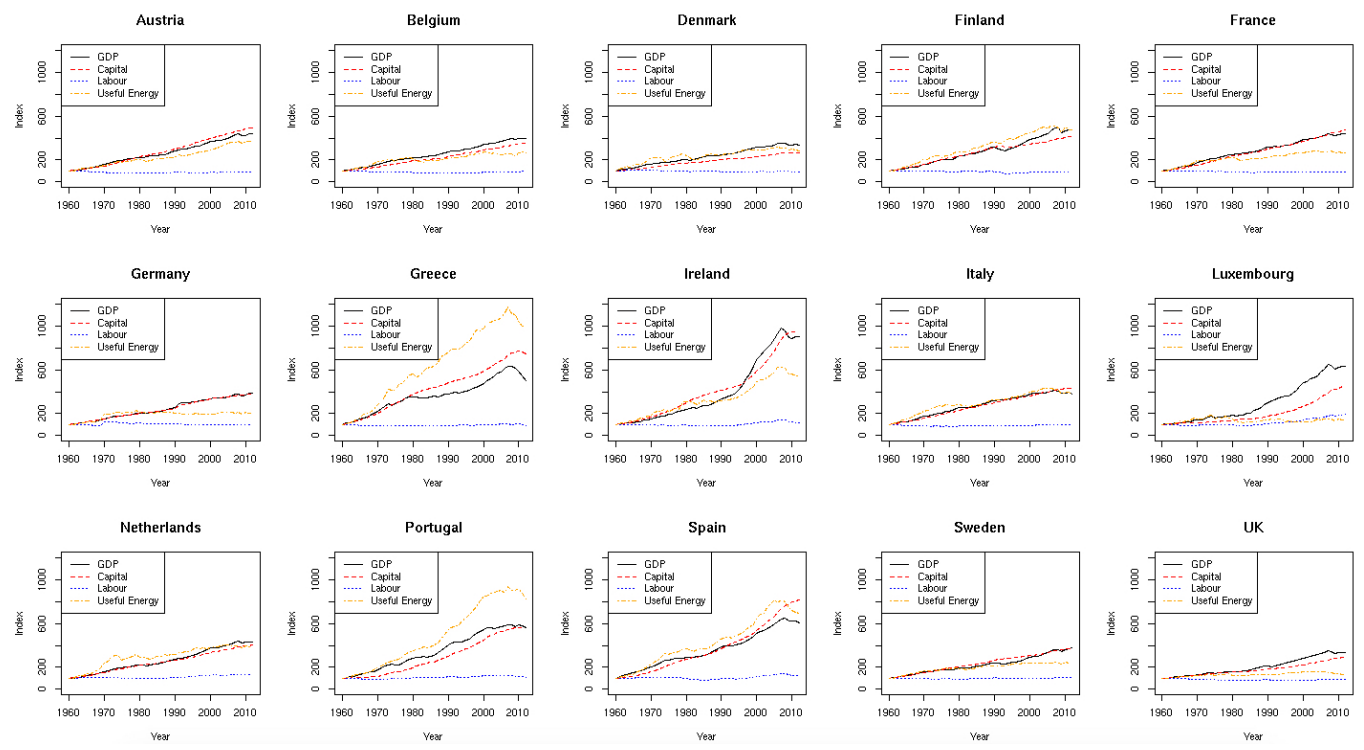

Figure 1: Index of GDP, capital, labour and useful energy

It is clear that economic growth (the GDP line) follows the same time trend (dynamics) as the growth of capital (Capital line) and useful energy (Useful Energy line). For some peripheral countries (e.g., Finland, Greece, Portugal and Spain) as well as the Netherlands, the growth rate of useful energy consumption has been higher than the growth rate of GDP. In other countries (e.g., Germany, France, and UK), the growth rate of capital closely matches the growth rate of GDP. With the exception of Luxembourg, the growth rate of labor input is much lower than the growth rate of GDP, useful energy and capital. These observed facts suggest that the drivers of economic growth are not the same for the EU15 countries.

Figure 2 shows the EU15 dynamics of the useful energy categories, namely mechanical work, light, heat, muscle work and other electrical uses (see Serrenho et al. (2014) for details):

- Mechanical drive: It comprises all types of energy conversion to physical work, regardless the energy source. The most common equipment in this category are steam turbines and internal combustion engines (depending on the source, natural gas, gasoline, diesel and aviation engines are distinguished). It also includes electric motors (e.g. for electric railways and trams). 

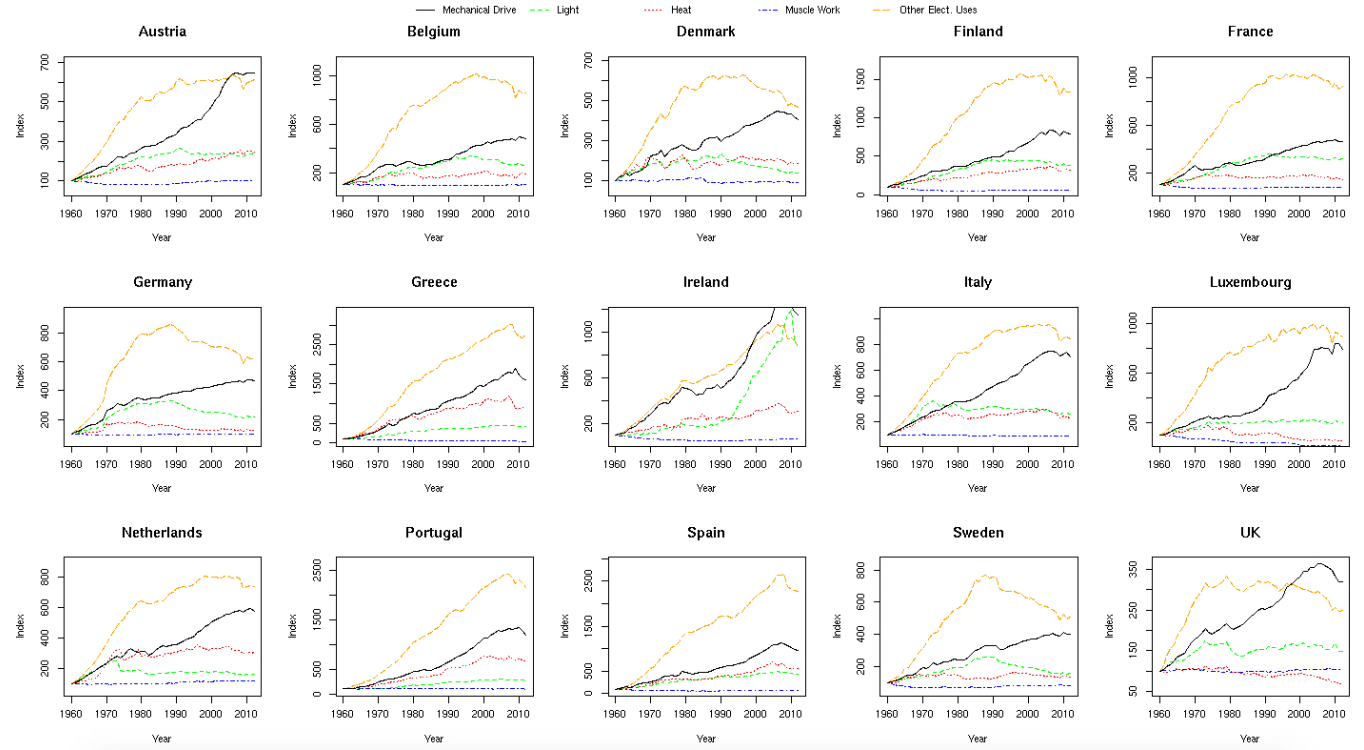

Figure 2: EU 15 useful energy categories: Mechanical work, light, heat, muscle work and other electrical uses.

- Light: It includes the total lighting end uses whatever the energy source. In most cases, light is now obtained from electricity.

- Heat: It includes all energy end-uses, including metallurgical and chemical processes where heat is used, either from fuel combustion or electricity (but not electrolysis).

- Muscle-brain work: This comprises useful energy from feed and food energy uses; i.e. the useful share of working animal or human intake of feed/food exergy, respectively.

- Other electrical work: It includes all electricity uses not included in the categories above. So it only includes electronic equipments, communications and electrochemical uses.

It is clear from Figure 2 that over the period 1970 to 2012, most of the growth occurred in other electrical uses (electronics, telecom) and mechanical drive. Mechanical drive has significantly grown over this period in all EU15 countries, mainly as a consequence of the popularization of automotive transport (fuelled primarily by petroleum oil products). 
Within the EU15, there are differences with respect to use of heat. It is notable that heat has plateaued or declined in countries hosting heavy industries before 1960, mainly as an indication of de-industrialization over the period 1960 to 2012 (e.g., the transfer of heavy industrial activity from Europe to China and India). On the other hand, heating uses increased mainly in Greece, Portugal, Spain, and Ireland, where a late industrialization followed World War II. Greece, Spain, Portugal, and Ireland exhibited a decline of the consumption of mechanical drive and other electrical uses after 2008.

Collectively Figure 2 and Figure 1 indicate that mechanical drive and electrical uses have more impact on economic growth than other end uses. The importance of mechanical drive on economic activity is particularly noticeable. These results show that the decoupling of economic growth and (useful) energy is not uniform across the different uses of energy.

\section{The empirical production function of the EU-15 countries}

Because it is not possible to provide a detailed discussion of all the EU15 countries in a single paper, we provide below some thought-provoking observations to stimulate the thinking of readers.

It is important to note that the marginal product of capital, labour and useful energy should be interpreted with respect to the changes in the (log) level of the factor of production such as percentage changes in the stock of capital or useful energy flows. This is because the proposed production func-

tion allows the magnitude of coefficients to vary according to the range of values of the factor of production (e.g., higher level of useful energy flows might have a higher coefficient compared with lower level of useful energy flows). Changes over time can only be assessed indirectly (e.g., the effect of the percentage change of capital stock, say over the period 2004-2012, on the percentage change of the marginal product of capital over the same period). Exploiting such non-linear relationships improve the performance of the model, and offer additional insights into the effects of the factors of production. Although some changes in the marginal product of a factor of production might be interpreted as "surprising", we note that dramatic changes in the marginal product or elasticities of a factor of production have been observed in other studies (e.g., Varoufakis and Sapsford (1991)). However, because of the smooth functions $f($.$) of the model of equation 2$ we do not necessarily assume that these changes are instantaneous (as it is as- 
sumed in conventional analyses of structural breaks with switching regression models). The smoothness of the function $f($.$) allows for 'transition periods',$ which are determined from the data.

In the remainder of this section we survey the historical relationships between GDP and the factors of production as well as the marginal products of capital, labor and useful energy for each of the EU-15 countries ${ }^{2}$. The overall policy implications are discussed in section 6 .

\subsection{Austria}

Figure 3 shows the relationship between the factors of production (capital, labor and useful energy) with GDP. The average $M P_{\text {Capital }}$ is 0.73 (with a standard deviation of 0.09 ), the average $M P_{\text {Labor }}$ is 0.58 (with a standard deviation of 0.41 ) while the $M P_{\text {UsefulEnergy }}$ is 0.12 - it is important to note the constant marginal product of useful energy throughout the period. Based on the average marginal product over the period of 1970 to 2012, the most important factor of production for Austria is capital.

Although the relationship between capital-GDP and useful energy-GDP are (almost) linear, the relationship of labor-GDP exhibits increasing returns to scale. In other words, higher levels of labor utilization have higher impact on economic growth (this is also evident from the high standard deviation around the average $M P_{\text {Labor }}$ noted above). Given the economic context in Austria in 2012, our results suggest that utilization of labor will have the highest immediate impact on the economic growth. This impact can be maximised if the government stimulates the growth in labour input by $1.5 \%$ from the 2012 level of labour input.

\footnotetext{
${ }^{2}$ Because the useful-energy-related dataset is less reliable between 1960 and 1970, the production function has been estimated using the period of 1970 to 2012.
} 


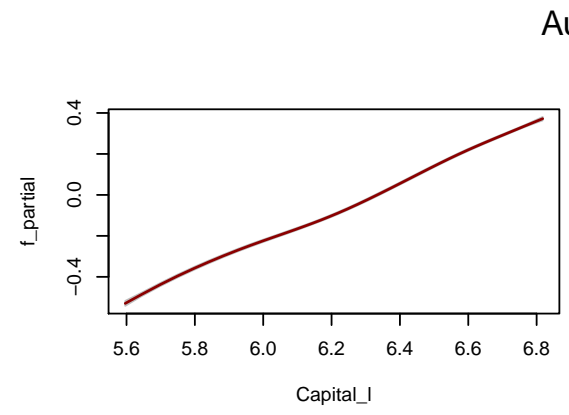

Austria
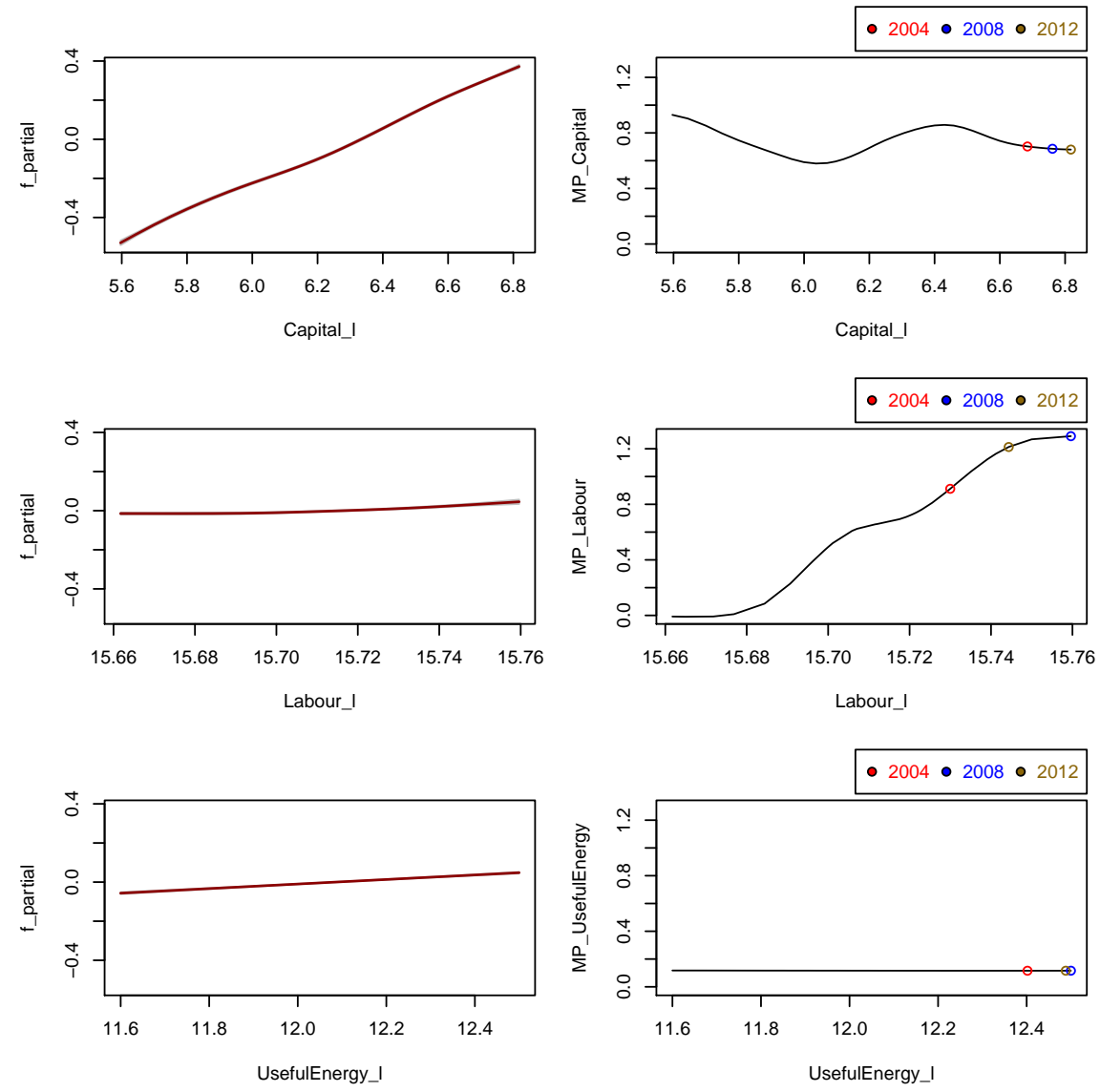

Figure 3: Factors of production and marginal products of Austria

With respect to the most "dramatic" change in the marginal product of the factors of production over the 2004-2012 period, we note the $33 \%$ increase of $M P_{\text {Labour }}$. This increase of the $M P_{\text {Labour }}$ is associated with $1 \%$ increase in the log-level of labour input along with $14 \%$ increase in the capital stock and $9 \%$ increase in the flows of useful energy. Thus, the $14 \%$ increase of capital stock (along with a marginal increase of labour input and useful energy flows) in Austria seems to give significant support in the labour productivity over the 2004-2012 period.

It is also important to note the increasing returns to scale experienced by the Austrian economy. The increasing returns to scale is primarily driven by labor input (although capital stock is also influential). This is particularly 
true since 2004.

\subsection{Belgium}

Figure 4 shows the relationship between the factors of production (capital, labor and useful energy) with GDP. The average $M P_{\text {Capital }}$ is 0.88 (with a standard deviation of 0.39 ), while the $M P_{\text {Labor }}$ is 0.39 and $M P_{\text {UsefulEnergy }}$ is 0.17 - it is important to note the constant marginal product of labour and useful energy throughout the period. Based on the average marginal product over the period of 1970 to 2012, the most important factor of production for Belgium is capital.

In the period from 2008 to 2012, the marginal product of labor was higher compared with the marginal product of capital while the marginal product of capital was almost equal to the marginal product of useful energy. Given the 2012 economic context in Belgium, enhanced utilization of labor input will also have the highest immediate impact on the economic activity. 


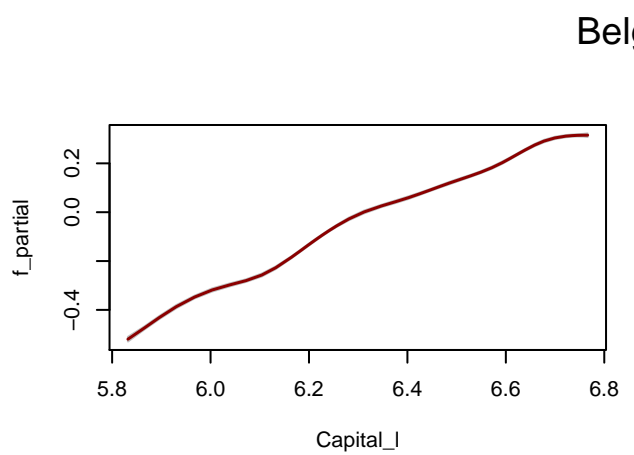

\section{Belgium}
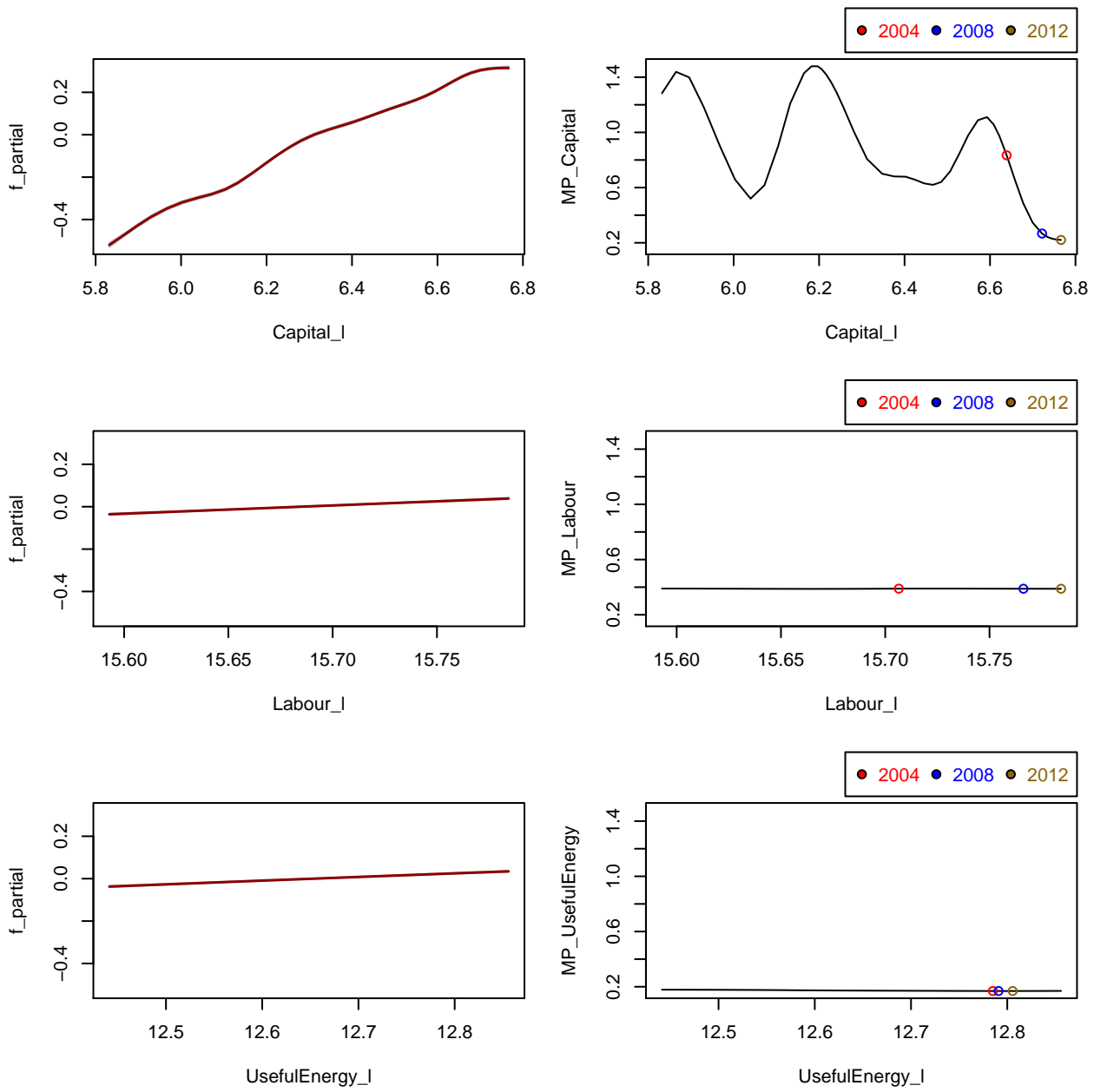

Figure 4: Factors of production and marginal products of Belgium

With respect to the most "dramatic" change in the marginal product of the factors of production over the 2004-2012 period, we note the $74 \%$ decrease of $M P_{\text {Capital }}$. This decrease of the $M P_{\text {Capital }}$ is associated with $13 \%$ increase in the capital stock along with $8 \%$ increase in the labour input and $2 \%$ increase in the flow of useful energy. Thus, the $13 \%$ increase of capital stock (along with increases of labour input and useful energy flows) leads to a drop in capital productivity over the 2004-2012 period, which seems to suggest under-utilisation of capital stock. 
Since 2004, the Belgium economy is mostly characterized by decreasing returns to scale.

\subsection{Denmark}

Figure 5 shows the relationship between the factors of production (capital, labor and useful energy) with GDP. The average $M P_{\text {Capital }}$ is 1.08 (with a standard deviation of 0.48 ), the average $M P_{\text {Labor }}$ is 0.37 (with a standard deviation of 0.32 ) and the $M P_{\text {UsefulEnergy }}$ is 0.26 (with a standard deviation of 0.26 ). Based on the average marginal product over the period of 1970 to 2012, the most important factor of production for Denmark is capital.

It is important to note the increasing marginal product of labor and useful energy in Denmark while the marginal product of capital exhibits a declining phase over the last few years. Furthermore at high levels of labor utilization, the effect of labor on economic growth levels off while the effect of useful energy increases. Given the economic context in Denmark in 2012, our results suggest that the increase of labor input by $11 \%$ and increase of useful energy flows by $10 \%$ will have the highest impact on the economic growth. 


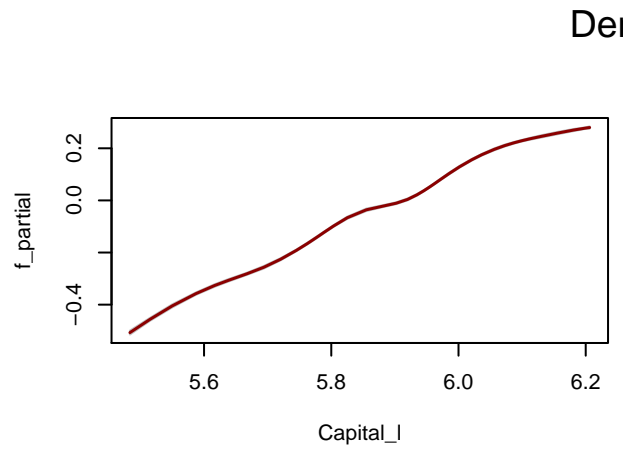

Denmark
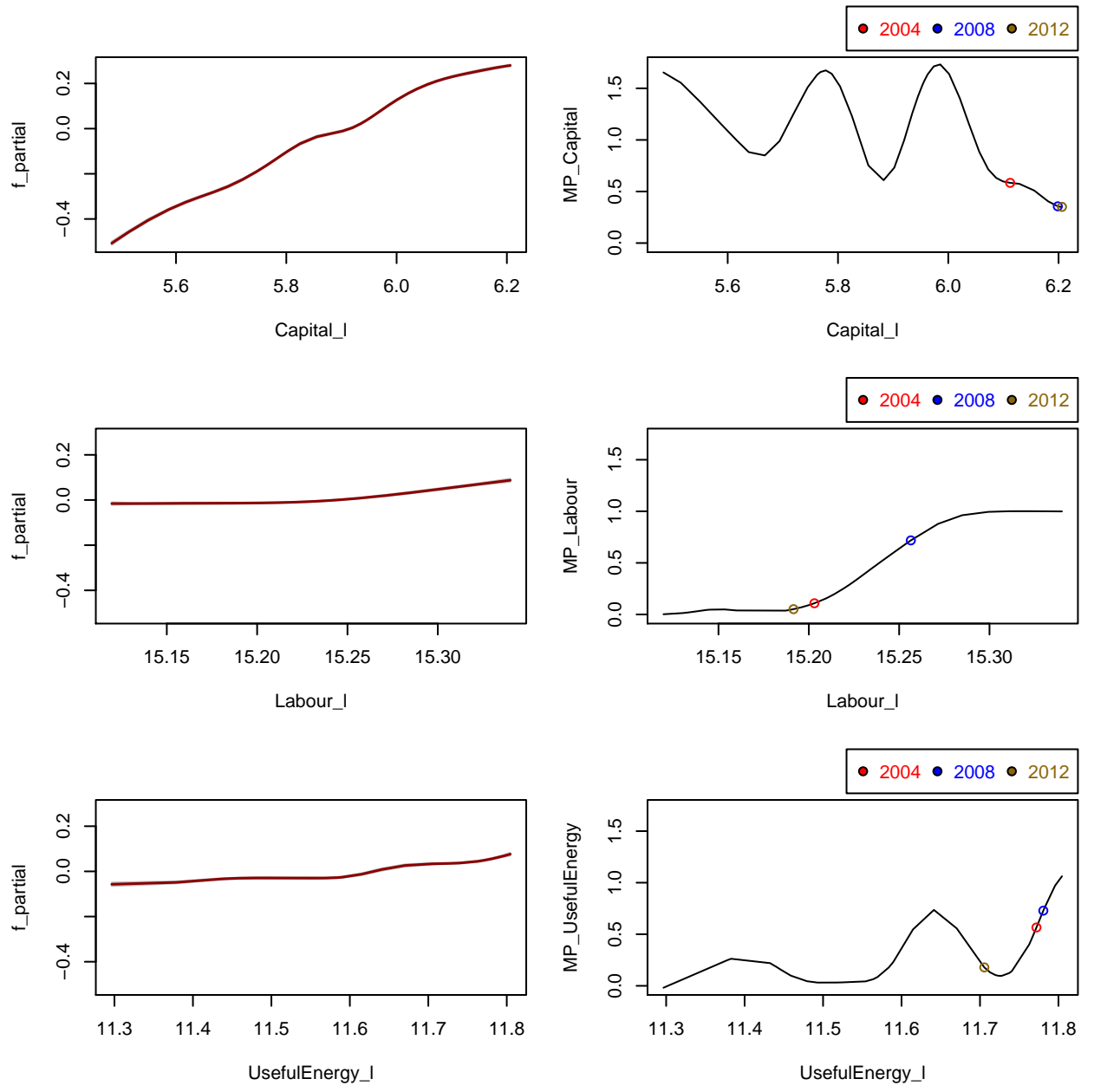

Figure 5: Factors of production and marginal products of Denmark

With respect to the most "dramatic" change in the marginal product of the factors of production over the 2004-2012 period, we note the $68 \%$ decrease of $M P_{U \text { usefulEnergy }}$. This decrease of the $M P_{\text {UsefulEnergy }}$ is associated with $6 \%$ decrease in the flow of useful energy along with $1 \%$ decrease in the labour input and $10 \%$ increase in the capital stock. It seems that the drop in the level of useful energy flows caused the dramatic reduction in marginal productivity of useful energy - useful energy flows are not optimal given the stock of capital in Denmark. 
The Denmark economy exhibits primarily increasing returns to scale.

\subsection{Finland}

Figure 6 shows the relationship between the factors of production (capital, labor and useful energy) with GDP. The average $M P_{\text {Labor }}$ is 0.79 (with a standard deviation of 0.08 ), the average $M P_{U \text { sefulEnergy }}$ is 0.55 (with a standard deviation of 0.24 ) while the $M P_{\text {Capital }}$ is 0.73 . Based on the average marginal product over the period of 1970 to 2012, the most important factor of production for Finland is labour. Note, however, the relatively small difference between average $M P_{\text {Labor }}$ and $M P_{\text {Capital }}$. The impact of useful energy flows on economic growth in some periods is also equally important, which is evident from the average $M P_{U \text { sefulEnergy }}$ and the associated standard deviation.

Given the 2012 economic context in Finland, our results suggest that improving the flow of useful energy will lead to the highest positive impact on the economic growth. However, a degree of 'convergence' is observed, meaning that all factors of production are almost equally important in terms of supporting the economy of Finland. 


\section{Finland}
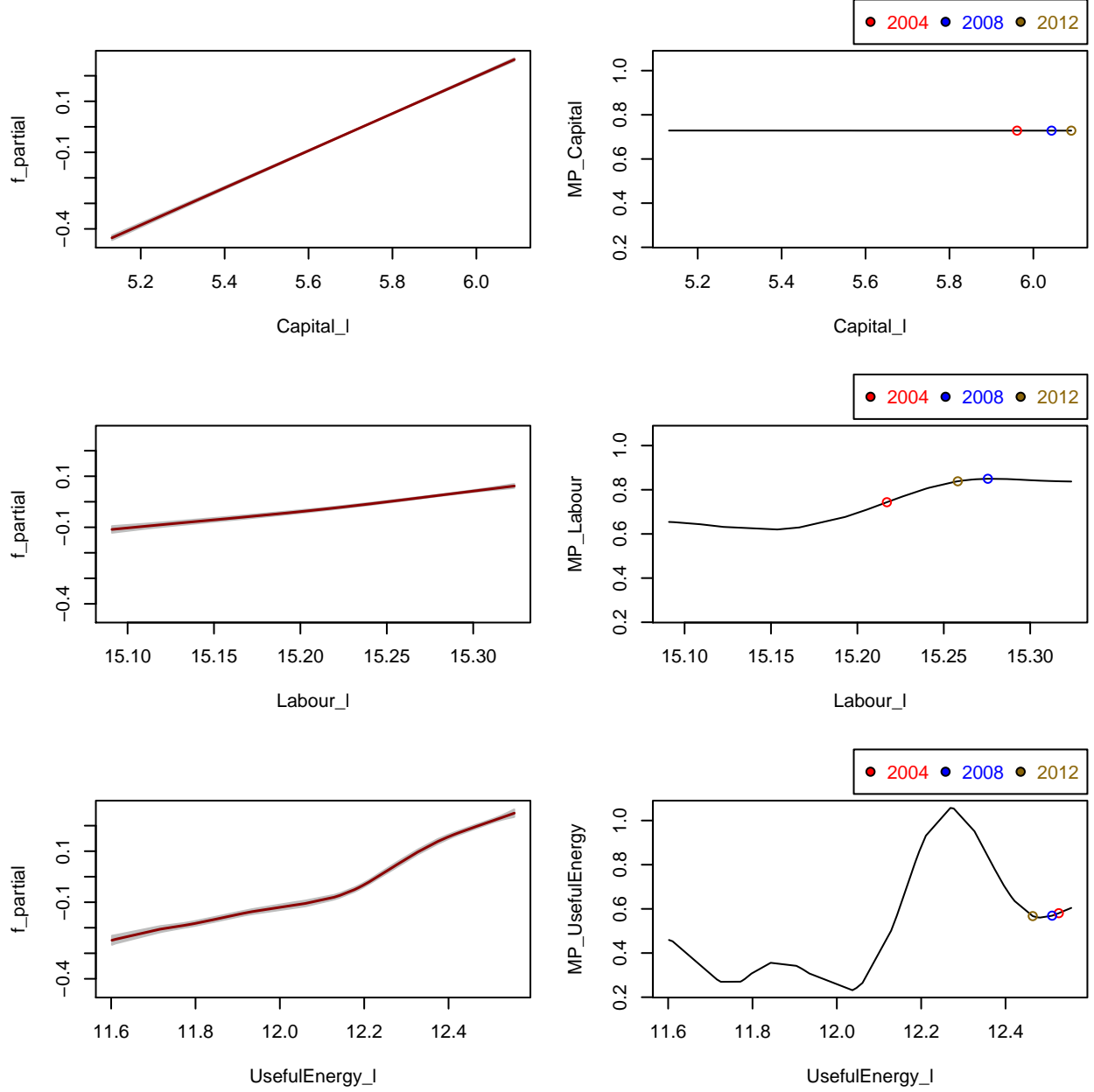

Figure 6: Factors of production and marginal products of Finland

With respect to the most "dramatic" change in the marginal product of the factors of production over the 2004-2012 period, we note the $12 \%$ increase of $M P_{\text {Labour }}$. This increase of the $M P_{\text {Labour }}$ is associated with $4 \%$ increase in the labour input along with $14 \%$ increase in the capital stock and $6 \%$ decrease in the flow of useful energy. 


\subsection{France}

Figure 7 shows the relationship between the factors of production (capital, labor and useful energy) with GDP. The average $M P_{\text {Capital }}$ is 0.80 (with a standard deviation of 0.30 ), while $M P_{\text {Labor }}$ is 0.67 and $M P_{\text {UsefulEnergy }}$ is 0.07 . Based on the average marginal product over the period of 1970 to 2012, the most important factor of production for France is capital.

However, the marginal product of capital decreases rapidly for high level of capital stock. This effectively suggests that by keeping constant the other two factors of production, enhanced investment in capital formulation in France will result in diminishing marginal returns of capital. Given the 2012 economic context in France, our results suggest that enhanced labor inputs in the economy will lead to the highest immediate impact on economic growth. 


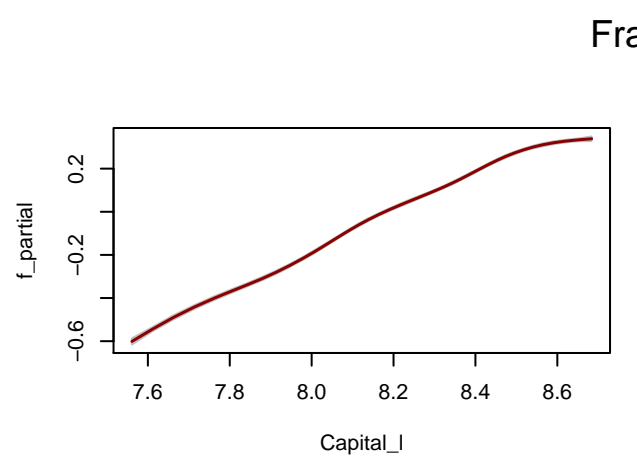

France
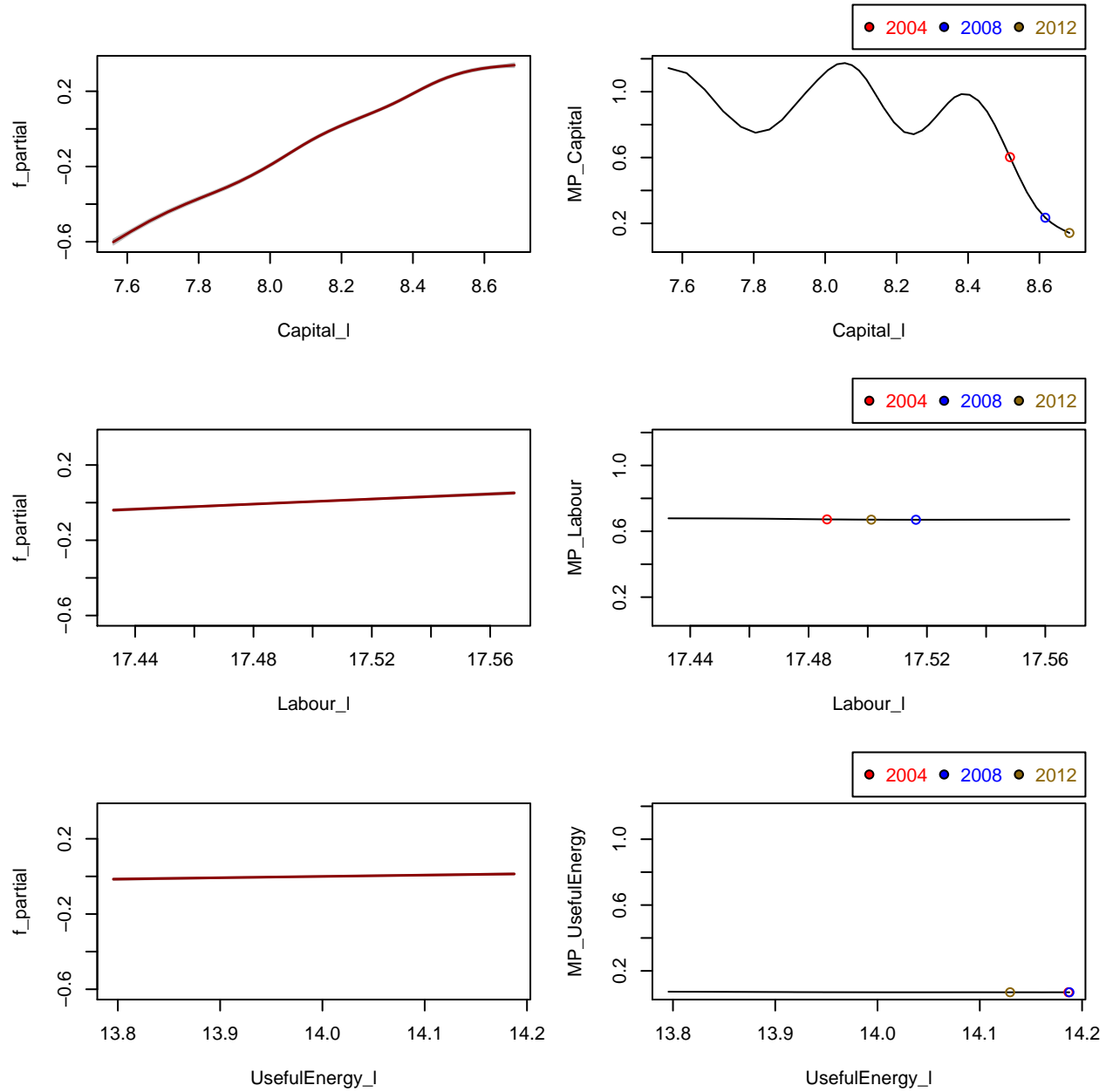

Figure 7: Factors of production and marginal products of France

With respect to the most "dramatic" change in the marginal product of the factors of production over the 2004-2012 period, we note the $76 \%$ decrease of $M P_{\text {Capital }}$. This decrease of the $M P_{\text {Capital }}$ is associated with $18 \%$ increase in the capital stock along with $2 \%$ increase in the labour input and $6 \%$ decrease in the flow of useful energy. It seems that the relatively high expansion of capital stock by $18 \%$ along with the decrease of useful energy flows caused the dramatic reduction in marginal product of capital. By way of two examples, in 2012 1\% change in capital stock was associated with 
$0.14 \%$ change in the GDP while in $20041 \%$ change in capital stock was associated with $0.60 \%$ change in the GDP of the French economy.

From about 2004 onwards, the French economy exhibits decreasing returns to scale or near constant returns to scale.

\subsection{Germany}

Figure 8 shows the relationship between the factors of production (capital, labor and useful energy) with GDP. The average $M P_{\text {Capital }}$ is 1.05 (with a standard deviation of 0.27 ), the average $M P_{\text {Labor }}$ is 0.68 (with a standard deviation of 0.34 ) while the $M P_{\text {UsefulEnergy }}$ is 0.27 . Based on the average marginal product over the period of 1970 to 2012, the most important factor of production for Germany is capital.

Given the 2012 economic context in Germany, our results suggest that investments in capital stock will have the highest immediate impact on the German economy (this needs to be done with care given the level of labor input and flows of useful energy). 

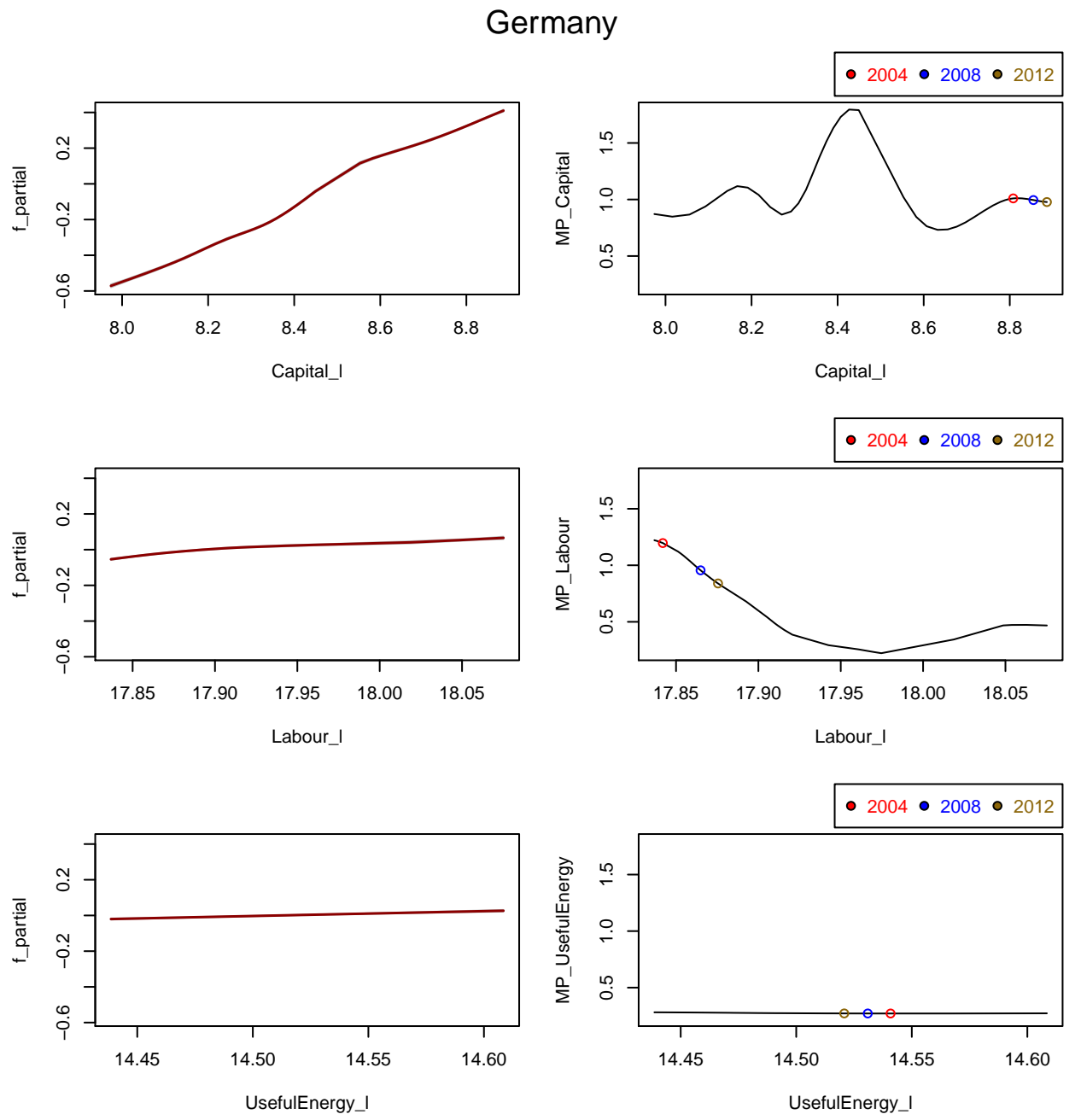

Figure 8: Factors of production and marginal products of Germany

With respect to the most "dramatic" change in the marginal product of the factors of production over the 2004-2012 period, we note the 30\% decrease of $M P_{\text {Labour }}$. This decrease of the $M P_{\text {Labour }}$ is associated with $3 \%$ increase in the labor input along with $8 \%$ increase in the capital stock and $2 \%$ decrease in the flow of useful energy. It seems that the increase of capital stock with the combined effect of the increase in labour input and decrease of useful energy flows caused the dramatic reduction in marginal productivity of labour in the German economy. 


\subsection{Greece}

Figure 9 shows the relationship between the factors of production (capital, labor and useful energy) with GDP. The average $M P_{\text {Labor }}$ is 0.82 (with a standard deviation of 0.73 ), the $M P_{\text {UsefulEnergy }}$ is 0.45 (with a standard deviation of 0.31 ) while the $M P_{\text {Capital }}$ is 0.30 . Based on the average marginal product over the period of 1970 to 2012, the most important factor of production for Greece is labour.

The marginal product of labor is highly variable, meaning that as the labor market of the Greek economy recovers the effects on economic activity will pass through various stages of increasing and diminishing marginal returns. As labour has the highest average impact on economic growth in Greece, the government should stimulate the growth of labour market by $11 \%$ to reach the maximum marginal product of labour. However, given the 2012 economic context for Greece, enhanced utilisation of useful energy flows should be given a priority. This suggests that the unbundling of the nearmonopolistic energy market in Greece can significantly affect the economic growth of the Greek economy. 


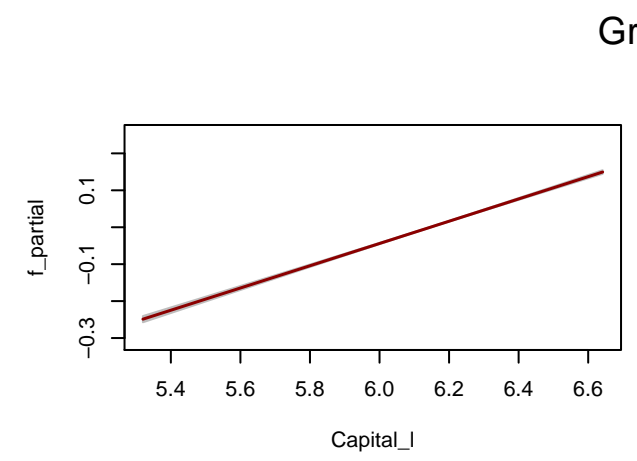

Greece
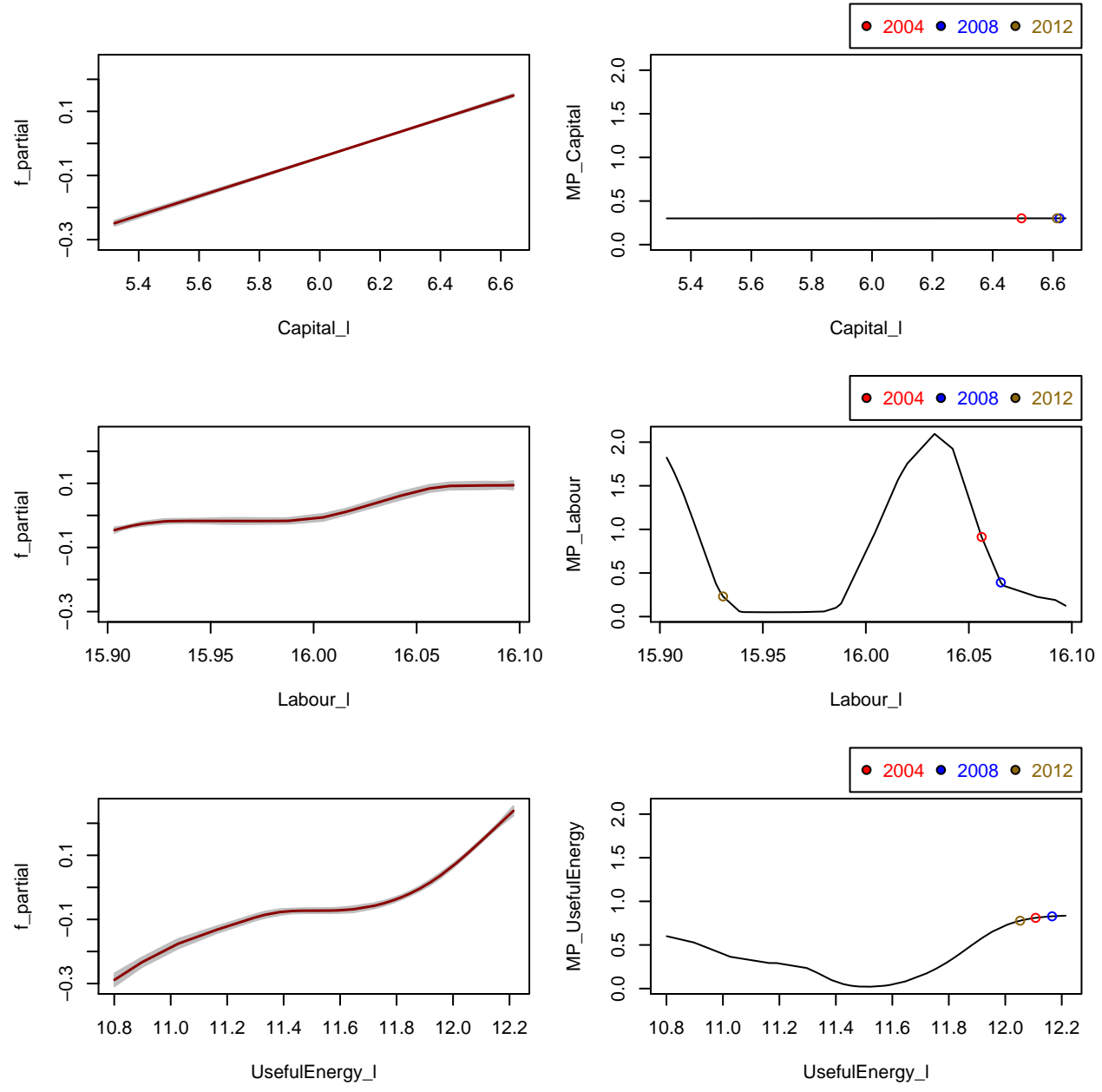

Figure 9: Factors of production and marginal products of Greece

With respect to the most "dramatic" change in the marginal product of the factors of production over the 2004-2012 period, we note the $74 \%$ decrease of $M P_{\text {Labour }}$. This decrease of the $M P_{\text {Labour }}$ is associated with $12 \%$ decrease in the labour input along with $12 \%$ increase in the capital stock and $5 \%$ increase in the flow of useful energy. This effectively explains the dramatic decrease in marginal productivity of labour as the result of $12 \%$ drop in labour input since 2004.

Since 2004, the increasing returns to scale of the Greek economy is pri- 
marily driven by useful energy.

\subsection{Ireland}

Figure 10 shows the relationship between the factors of production (capital, labour and useful energy) with GDP. The average $M P_{\text {Capital }}$ is 1.04 (with a standard deviation of 0.65 ), the average $M P_{\text {Labor }}$ is 0.51 (with a standard deviation of 0.28 ) while the $M P_{U \text { sefulEnergy }}$ is close to zero, meaning that the economy of Ireland is mainly driven by labour input and capital stock. Based on the average marginal product over the period of 1970 to 2012, the most important factor of production is capital.

The marginal product of capital is highly variable while we observe diminishing marginal returns for high levels of capital stock. The marginal product

of labor exhibits increasing marginal returns for levels of labor. Given the economic context in Ireland in 2012, our results suggest that the implementation of a policy to increase the labor input by $15 \%$. 

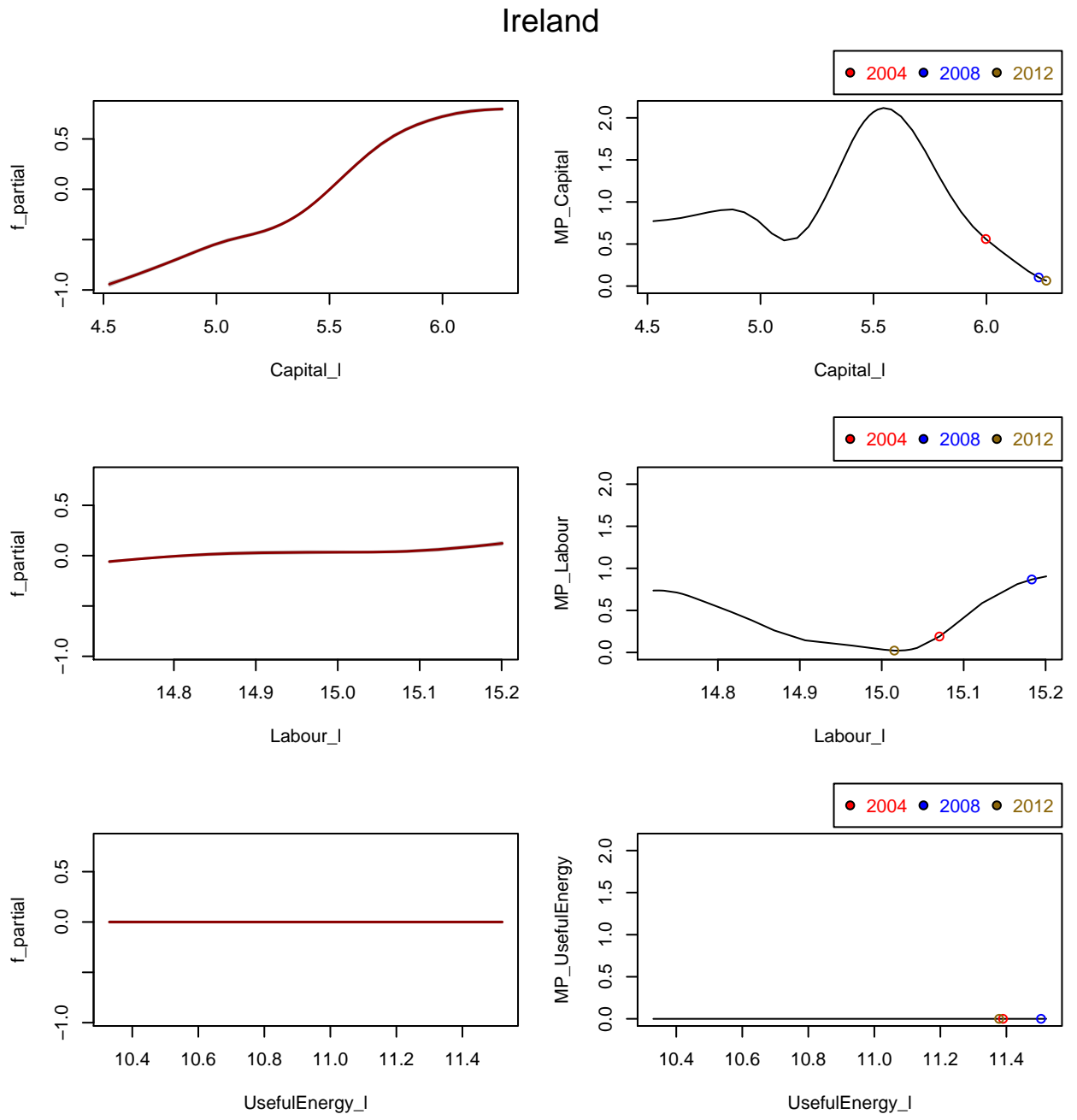

Figure 10: Factors of production and marginal products of Ireland

With respect to the most "dramatic" change in the marginal product of the factors of production over the 2004-2012 period, we note the $88 \%$ decrease of $M P_{\text {Capital }}$ (a similar case can be made for the $M P_{\text {Labour }}$ ). This decrease of $M P_{\text {Capital }}$ is associated with $31 \%$ increase in the level of capital stock along with $5 \%$ decrease in the level of labor input and 1\% decrease of useful energy flows. 


\subsection{Italy}

Figure 11 shows the relationship between the factors of production (capital, labor and useful energy) with GDP. The average $M P_{\text {Capital }}$ is 0.49 (with a standard deviation of 0.22 ), while the $M P_{\text {Labor }}$ is 0.28 and the $M P_{U \text { usefulEnergy }}$ is 0.45 . Based on the average marginal product over the period of 1970 to 2012, the most important factor of production for Italy is capital (however, useful energy has also a comparable marginal product most of the time).

We note the long diminishing marginal return of capital. Although, we observe that this diminishing marginal return of capital reverses for high levels of capital utilization. For high levels of capital and useful energy, the marginal product of useful energy is higher compared with the marginal products of capital and labour. Given the 2012 economic context in Italy, our results suggest that increase of useful energy flows will have immediate positive impact on the economic growth of Italy (however, an investment plan to improve the capital stock will also have important positive impact on the economy of Italy). 


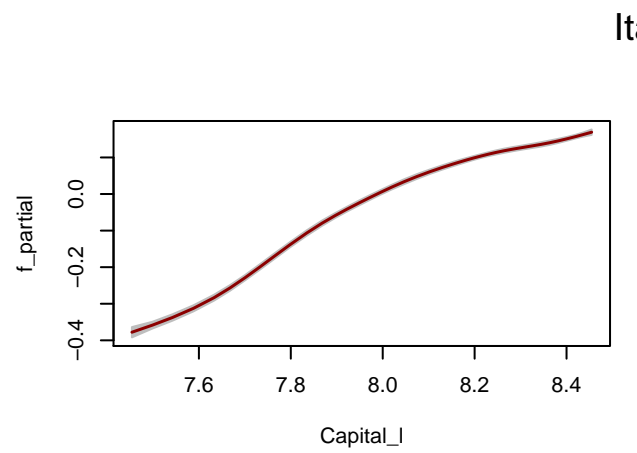

Italy
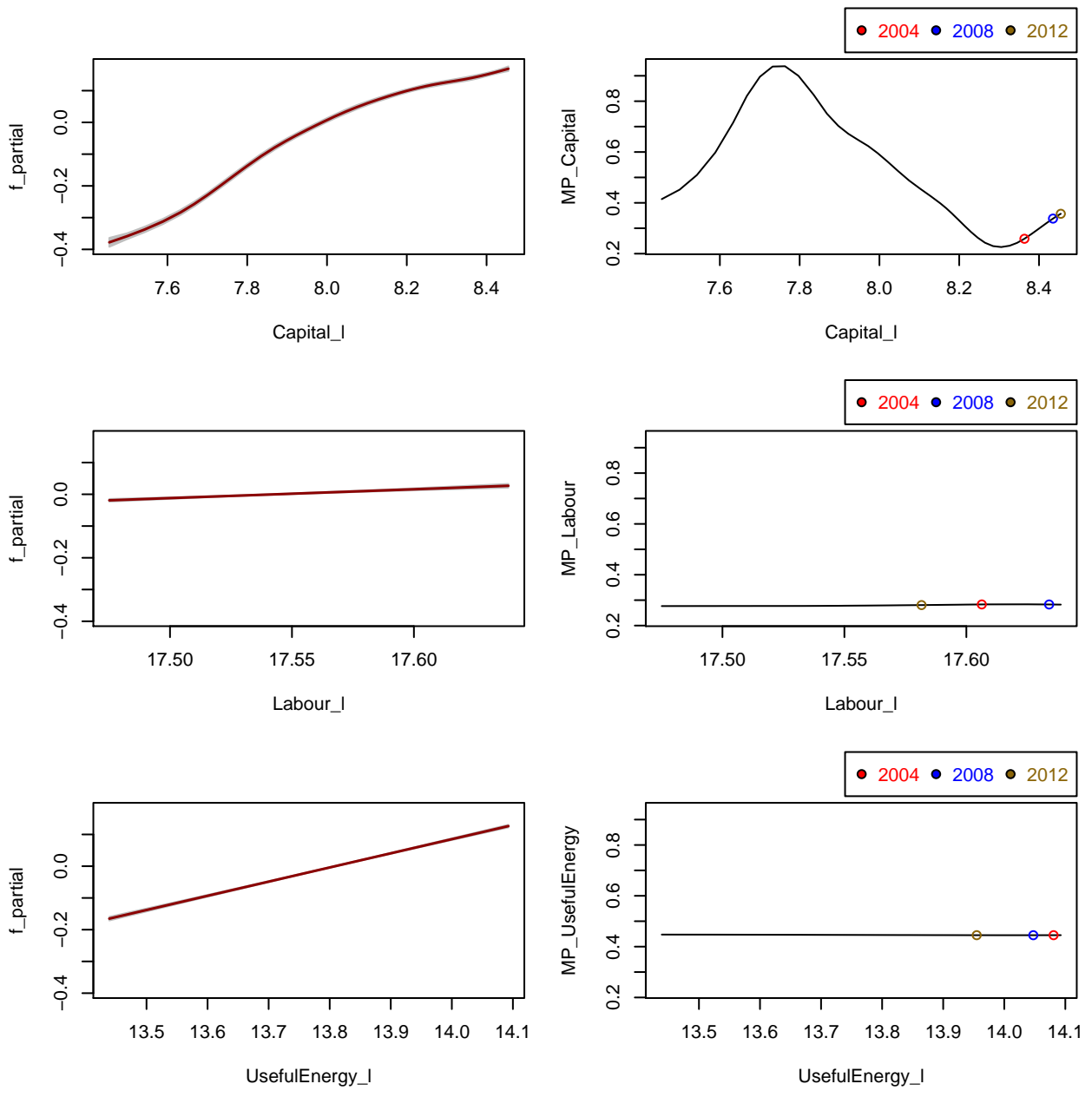

Figure 11: Factors of production and marginal products of Italy

With respect to the most "dramatic" change in the marginal product of the factors of production over the 2004-2012 period, we note the $38 \%$ increase of $M P_{\text {Capital }}$. This increase of the $M P_{\text {Capital }}$ is associated with $10 \%$ increase in the capital stock along with $2 \%$ decrease in the labour input and $12 \%$ decrease of useful energy flows. This seems to imply a level of a "correction" of the capital stock with the levels of labour input and useful energy flows in the Italian economy. This correction does not violate the suggestion to increase the level of useful energy flows given the 2012 level of capital stock. 


\subsection{Luxembourg}

Figure 12 shows the relationship between the factors of production (capital, labor and useful energy) with GDP. The average $M P_{\text {Capital }}$ is 1.03 (with a standard deviation of 0.74 ), the average $M P_{\text {UsefulEnergy }}$ is 0.27 (with a standard deviation of 0.14) while the $M P_{\text {Labor }}$ is 0.50 . Based on the average marginal product over the period of 1970 to 2012, the most important factor of production for Luxembourg is capital. Note, however, the rapid diminishing marginal returns for high levels of capital stocks and the increasing marginal returns of useful energy.

Given the economic context in Luxembourg in 2012, our results suggest that government should increase the level labor input and level of useful energy flows in the economy of Luxembourg. 


\section{Luxembourg}
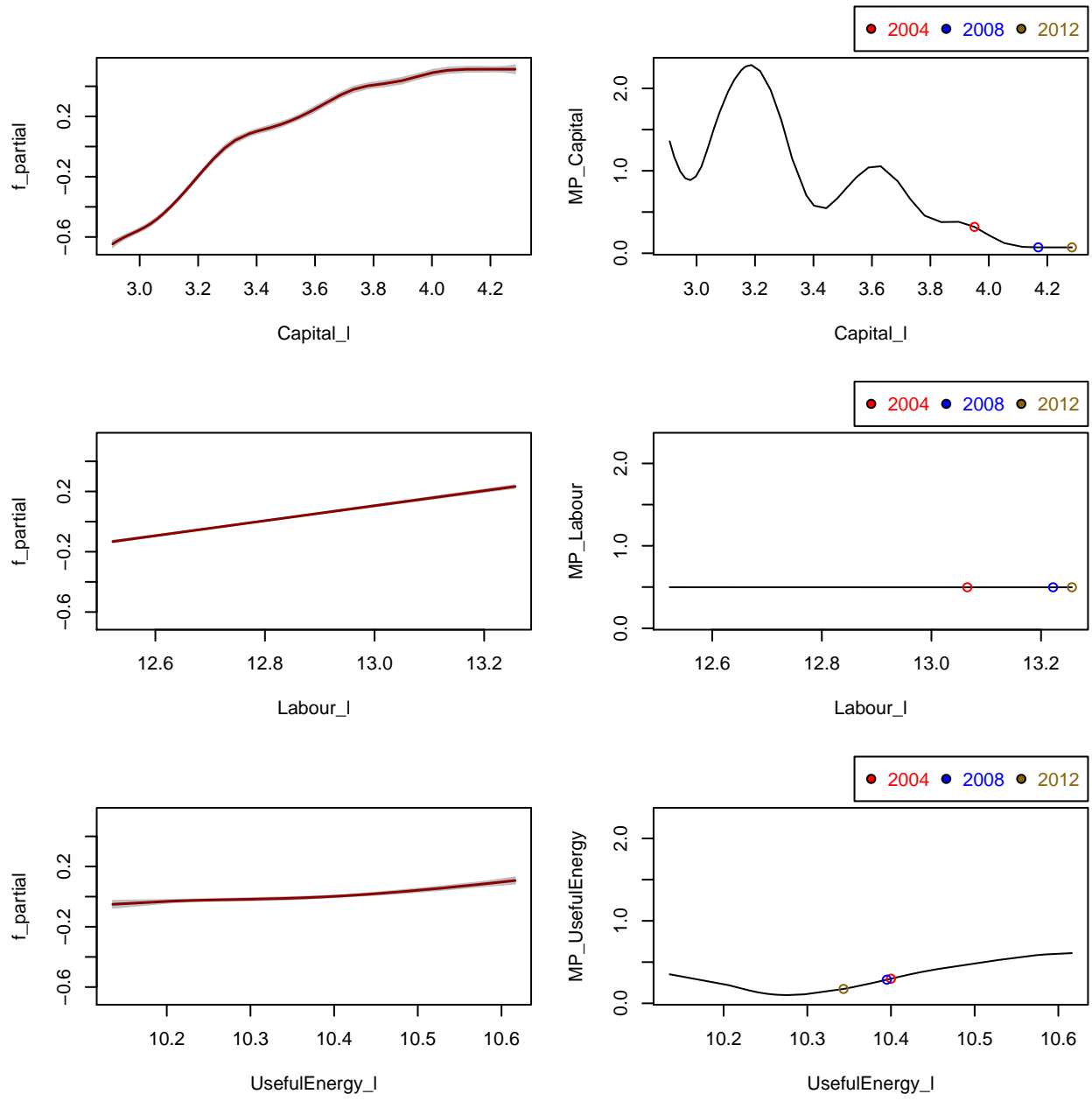

Figure 12: Factors of production and marginal products of Luxembourg

With respect to the most "dramatic" change in the marginal product of the factors of production over the 2004-2012 period, we note the $78 \%$ decrease of $M P_{\text {Capital }}$. This decrease of the $M P_{\text {Capital }}$ is associated with $40 \%$ increase in the capital stock along with $21 \%$ increase in the labour input and $6 \%$ decrease in the flow of useful energy. Thus, the $40 \%$ increase of capital stock in Luxembourg have negative effect on the marginal product of capital possibly because of the under-utilisation of the capital stock. This is supported by the diminishing returns to scale of the capital stock. 


\subsection{Netherlands}

Figure 13 shows the relationship between the factors of production (capital, labor and useful energy) with GDP. The average $M P_{\text {Capital }}$ is 0.86 (with a standard deviation of 0.22 ), the average $M P_{U \text { sefulEnergy }}$ is 0.04 (with a standard deviation of 0.04 ) while the $M P_{\text {Labor }}$ 0.44. Based on the average marginal product over the period of 1970 to 2012, the most important factor of production for Netherlands is capital (note, however, that the marginal product of capital is decreasing).

Given the 2012 economic context in Netherlands, our results suggest that economic policy in the Netherlands should increase the level of labour input

to achieve the highest immediate impact on the economic growth in the Netherlands. 

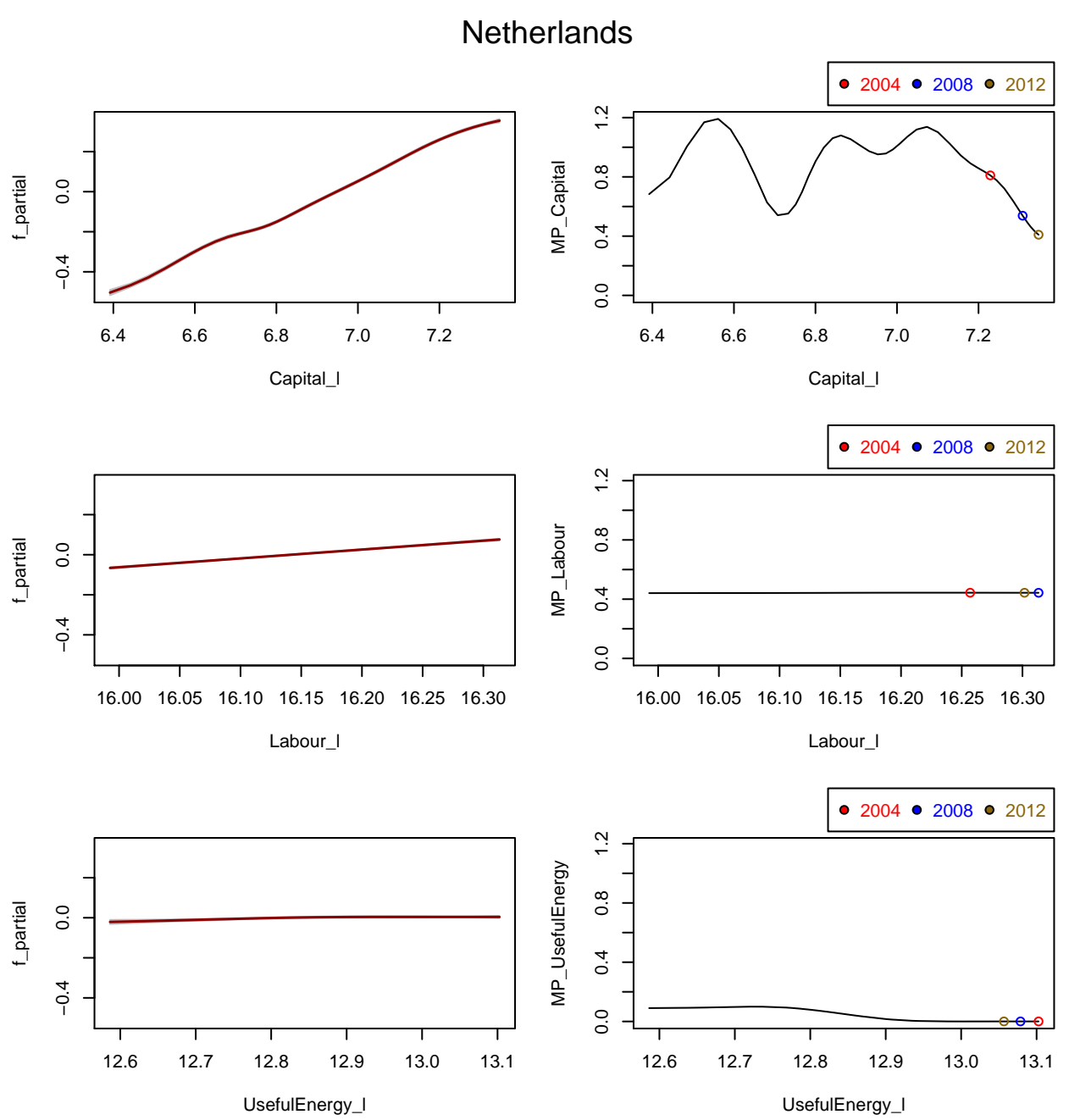

Figure 13: Factors of production and marginal products of Netherlands

With respect to the most "dramatic" change in the marginal product of the factors of production over the 2004-2012 period, we note the 50\% decrease of $M P_{\text {Capital }}$. This increase of the $M P_{\text {Capital }}$ is associated with $13 \%$ increase in the capital stock along with $5 \%$ increase in the labour input and $4 \%$ decrease in the flow of useful energy. Thus, the increase of capital stock and decline of useful energy flows in Netherlands seems to have a negative effect on the marginal product of capital over the 2004-2012 period. 


\subsection{Portugal}

Figure 14 shows the relationship between the factors of production (capital, labor and useful energy) with GDP. The average $M P_{\text {Capital }}$ is 0.76 (with a standard deviation of 0.49 ), the average $M P_{\text {Labor }}$ is 0.48 (with a standard deviation of 0.44 ) while the $M P_{U \text { sefulEnergy }}$ is 0.01 . Based on the average marginal product over the period of 1970 to 2012, the most important factor of production for Portugal is capital.

However, we note the highly erratic marginal product of capital and the increasing marginal returns of labor. Given the economic context in Portugal in 2012, our results suggest that government should seek ways to increase the level of labor input and the level of capital stock. This means that the government in Portugal should device a joint captal investment plan and labor market reforms to enhance the level of labor input. 


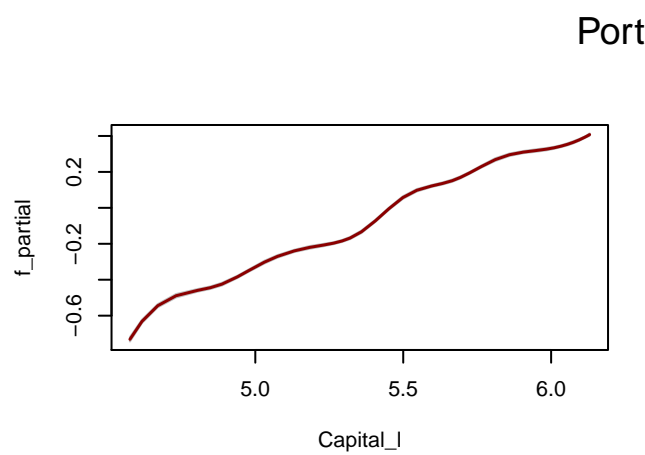

\section{Portugal}
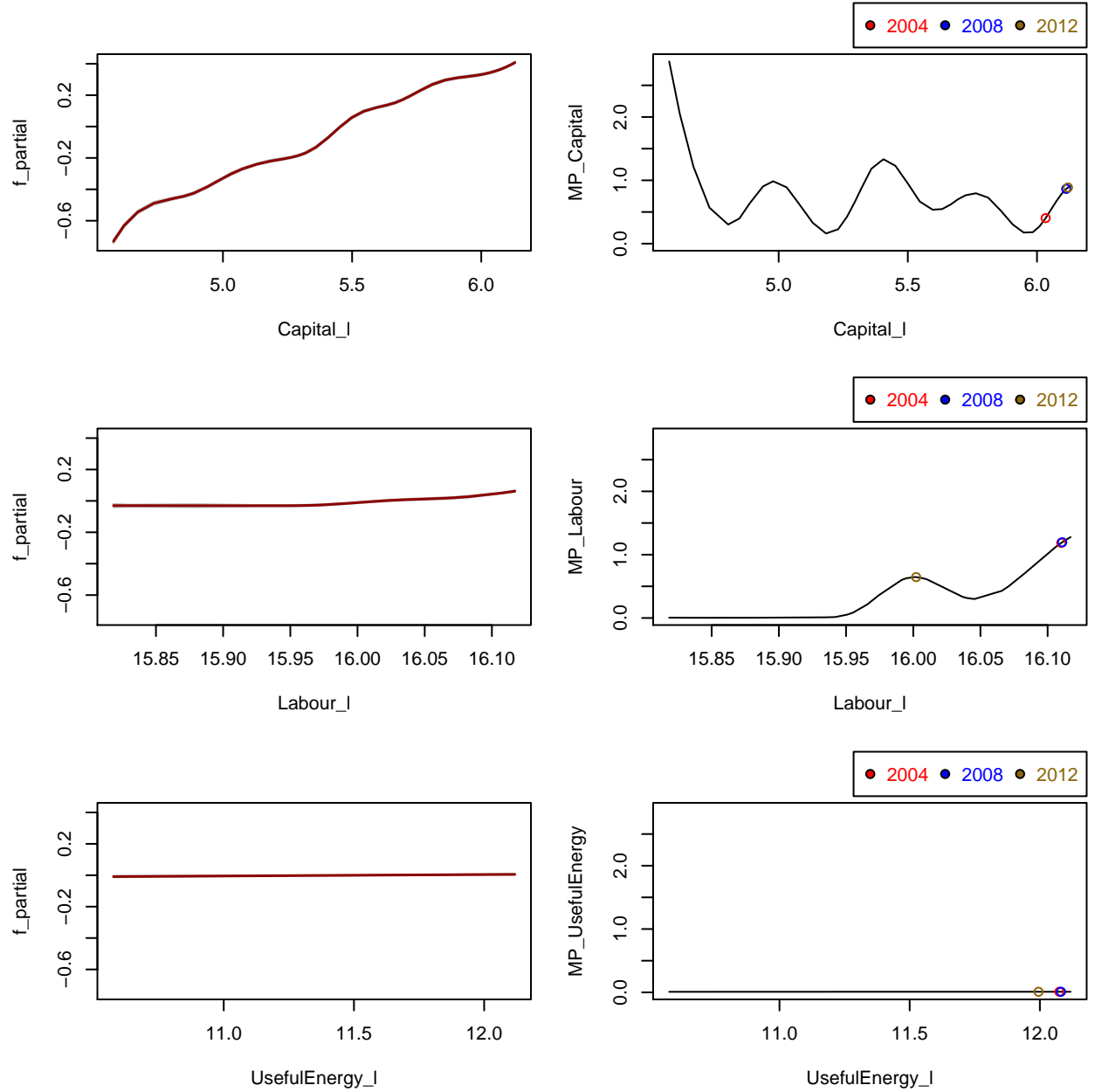

Figure 14: Factors of production and marginal products of Portugal

With respect to the most "dramatic" change in the marginal product of the factors of production over the 2004-2012 period, we note the $120 \%$ increase of $M P_{\text {Capital }}$. This increase of the $M P_{\text {Capital }}$ is associated with $10 \%$ increase in the capital stock along with $10 \%$ decrease in the labour input and $8 \%$ decrease in the flow of useful energy. 


\subsection{Spain}

Figure 15 shows the relationship between the factors of production (capital, labor and useful energy) with GDP. The average $M P_{\text {Capital }}$ is 0.65 (with a standard deviation of 0.26 ), the average $M P_{\text {Labor }}$ is 0.37 (with a standard deviation of 0.14 ) while the $M P_{\text {UsefulEnergy }}$ is 0.001 . Based on the average marginal product over the period of 1970 to 2012, the most important factor of production for Portugal is capital. However, we note the highly erratic marginal product of capital and the increasing marginal product of labour.

Given the 2012 economic context in Spain, our results suggest to increase the level of labor input by $14 \%$ to achieve the highest level of $M P_{\text {Labor }}$ and hence the highest impact on the economic growth. However, an investment

plan to increase the capital stock will also have substantial positive effect on the economy of Spain. 


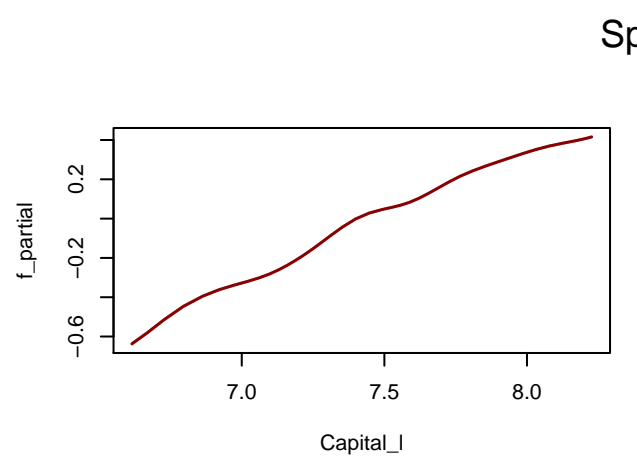

\section{Spain}
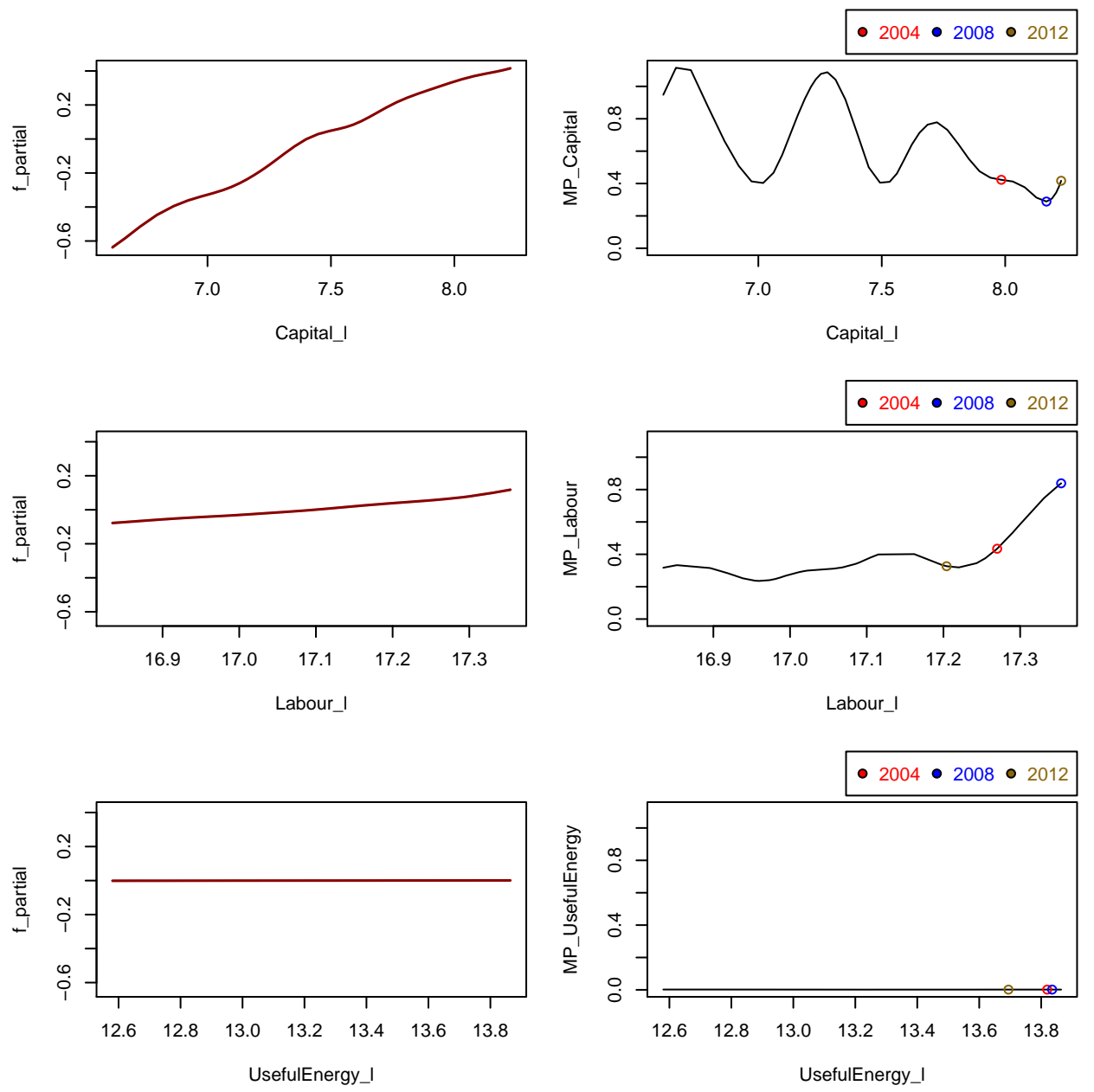

Figure 15: Factors of production and marginal products of Spain

With respect to the most "dramatic" change in the marginal product of the factors of production over the 2004-2012 period, we note the $25 \%$ decrease of $M P_{\text {Labour }}$. This decrease of the $M P_{\text {Labour }}$ is associated with $6 \%$ decrease in the labour input along with $27 \%$ increase in the capital stock. Thus, the $6 \%$ decrease of labour input (along with a marginal increase of capital stock) in Spain seems to have a negative effect on labour productivity over the 2004-2012 period. 


\subsection{Sweden}

Figure 16 shows the relationship between the factors of production (capital, labor and useful energy) with GDP. The average $M P_{\text {Capital }}$ is 0.85 (with a standard deviation of 0.57 ), the $M P_{\text {Labor }}$ is 0.70 while the $M P_{\text {UsefulEnergy }}$ is 0.27. Based on the average marginal product over the period of 1970 to 2012, the most important factor of production for Sweden is capital. However, note the diminishing returns of capital at high levels of capital stock.

Given the 2012 economic context in Sweden, our results suggest that government should increase the level of labour input in order to enhance the economic performance of the economy in Sweden. 


\section{Sweden}
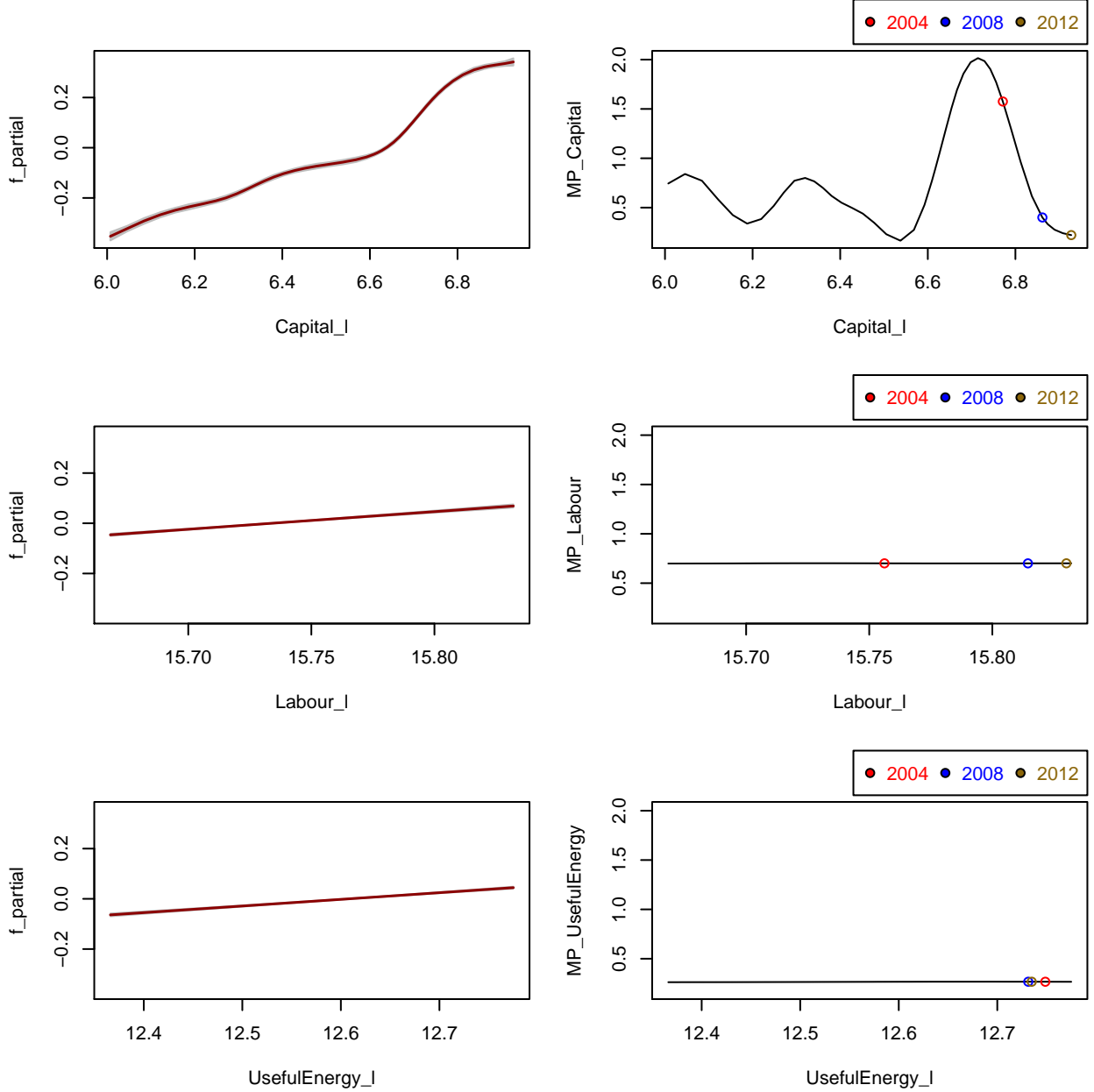

Figure 16: Factors of production and marginal products of Sweden

With respect to the most "dramatic" change in the marginal product of the factors of production over the 2004-2012 period, we note the $85 \%$ decrease of $M P_{\text {Capital }}$. This decrease of the $M P_{\text {Capital }}$ is associated with $17 \%$ increase in the capital stock and a decrease of useful energy flows.

\subsection{5. $U K$}

Figure 17 shows the relationship between the factors of production (capital, labor and useful energy) with GDP. The average $M P_{\text {Capital }}$ is 1.19 (with 
a standard deviation of 0.41 ), the average $M P_{\text {Labor }}$ is 0.41 (with a standard deviation of 0.09 ) while the $M P_{\text {UsefulEnergy }}$ is 0.48 . Based on the average marginal product over the period of 1970 to 2012, the most important factor of production for UK is capital.

Given the 2012 economic context in UK, our results suggest that the UK economy will benefit most by a coordinating increase of the levels of labor input and capital stock as well as useful energy flows with a priority on capital stock.
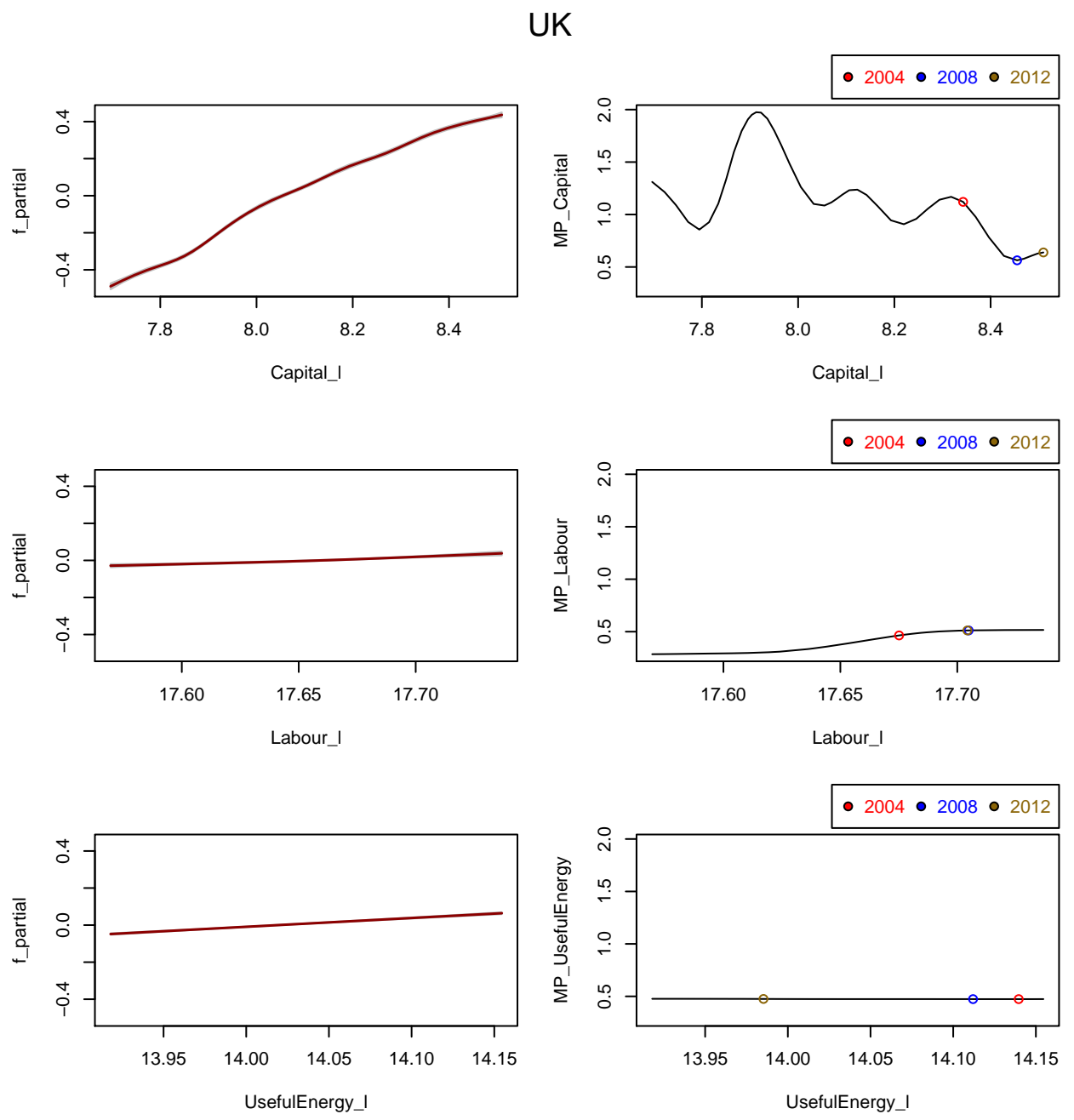

Figure 17: Factors of production and marginal products of the UK 
With respect to the most "dramatic" change in the marginal product of the factors of production over the 2004-2012 period, we note the $43 \%$ decrease of $M P_{\text {Capital }}$. This decrease of the $M P_{\text {Capital }}$ is associated with $18 \%$ increase in the level of capital stock along with $3 \%$ increase in the level of labor input and $14 \%$ decrease in the useful energy flows. Thus, the increase of the level of capital stock along with the decrease of useful energy flows seems to have a negative effect on the marginal product of capital over the 2004-2012 period.

To summarise, table 2 summarises the average marginal product of capital, labor and useful energy over the period 1970-2012. In order to get an indication of the uncertainty around these estimates, we provide estimates of the standard deviation of the marginal products. However, because of the use of non-linear smooth functions, the marginal product depends on the $(\log )$ input levels of the factors of production. For completeness, table 3 shows the estimates of the marginal product of capital, labor and useful energy based on the input levels of the factors of production as of 2012 . 


\begin{tabular}{|c|c|c|c|}
\hline Country & $\begin{array}{c}\text { Average } M P_{\text {Capital }} \\
\text { (standard deviation) }\end{array}$ & $\begin{array}{c}\text { Average } M P_{\text {Labor }} \\
\text { (standard deviation) }\end{array}$ & $\begin{array}{c}\text { Average } M P_{\text {UsefulEnergy }} \\
\text { (standard deviation) }\end{array}$ \\
\hline Austria & $\begin{array}{c}0.73 \\
(0.09)\end{array}$ & $\begin{array}{c}0.58 \\
(0.41)\end{array}$ & 0.12 \\
\hline Belgium & $\begin{array}{c}0.88 \\
(0.39)\end{array}$ & 0.39 & 0.17 \\
\hline Denmark & $\begin{array}{c}1.08 \\
(0.48) \\
\end{array}$ & $\begin{array}{c}0.37 \\
(0.32)\end{array}$ & $\begin{array}{c}0.26 \\
(0.26)\end{array}$ \\
\hline Finland & 0.73 & $\begin{array}{c}0.79 \\
(0.08)\end{array}$ & $\begin{array}{c}0.55 \\
(0.24)\end{array}$ \\
\hline France & $\begin{array}{c}0.80 \\
(0.30)\end{array}$ & 0.67 & 0.07 \\
\hline Germany & $\begin{array}{c}1.05 \\
(0.27) \\
\end{array}$ & $\begin{array}{c}0.68 \\
(0.34) \\
\end{array}$ & 0.27 \\
\hline Greece & 0.30 & $\begin{array}{c}0.82 \\
(0.73) \\
\end{array}$ & $\begin{array}{c}0.45 \\
(0.31) \\
\end{array}$ \\
\hline Ireland & $\begin{array}{c}1.04 \\
(0.65) \\
\end{array}$ & $\begin{array}{c}0.51 \\
(0.28) \\
\end{array}$ & $\sim 0$ \\
\hline Italy & $\begin{array}{c}0.49 \\
(0.22)\end{array}$ & 0.28 & 0.45 \\
\hline Luxembourg & $\begin{array}{c}1.03 \\
(0.74)\end{array}$ & 0.50 & $\begin{array}{c}0.27 \\
(0.14)\end{array}$ \\
\hline Netherlands & $\begin{array}{c}0.86 \\
(0.22) \\
\end{array}$ & 0.44 & $\begin{array}{c}0.04 \\
(0.04)\end{array}$ \\
\hline Portugal & $\begin{array}{c}0.76 \\
(0.49) \\
\end{array}$ & $\begin{array}{c}0.48 \\
(0.44) \\
\end{array}$ & 0.01 \\
\hline Spain & $\begin{array}{c}0.65 \\
(0.26)\end{array}$ & $\begin{array}{c}0.37 \\
(0.14)\end{array}$ & $\sim 0$ \\
\hline Sweden & $\begin{array}{c}0.85 \\
(0.57)\end{array}$ & 0.70 & 0.27 \\
\hline UK & $\begin{array}{c}1.19 \\
(0.41) \\
\end{array}$ & $\begin{array}{c}0.41 \\
(0.09) \\
\end{array}$ & 0.48 \\
\hline
\end{tabular}

Table 2: EU-15 - Average marginal product of capital, labor and useful energy over the period 1970-2012. 


\begin{tabular}{lcccc}
\hline \hline Country & MP Capital & $M P_{\text {Labor }}$ & MP $P_{\text {UsefulEnergy }}$ & $\begin{array}{c}\text { GDP growth rate } \\
\text { (2004-2012) }\end{array}$ \\
\hline Austria & 0.68 & 1.21 & 0.12 & 0.126 \\
Belgium & 0.22 & 0.39 & 0.17 & 0.093 \\
Denmark & 0.35 & 0.05 & 0.18 & 0.028 \\
Finland & 0.73 & 0.84 & 0.57 & 0.088 \\
France & 0.14 & 0.67 & 0.07 & 0.07 \\
Germany & 0.98 & 0.84 & 0.27 & 0.112 \\
Greece & 0.30 & 0.23 & 0.78 & -0.12 \\
Ireland & 0.06 & 0.02 & $\sim 0$ & 0.086 \\
Italy & 0.36 & 0.28 & 0.45 & -0.023 \\
Luxembourg & 0.07 & 0.50 & 0.17 & 0.146 \\
Netherlands & 0.41 & 0.44 & $\sim 0.001$ & 0.085 \\
Portugal & 0.89 & 0.65 & 0.01 & -0.01 \\
Spain & 0.42 & 0.33 & $\sim 0$ & 0.061 \\
Sweden & 0.22 & 0.70 & 0.27 & 0.15 \\
UK & 0.64 & 0.51 & 0.48 & 0.062 \\
\hline
\end{tabular}

Table 3: EU-15 - Marginal product of capital, labor and useful energy in 2012 with GDP growth rate from 2004 to 2012.

\section{Conclusions and policy implications}

As a way of addressing the economic growth enigma for the EU-15 countries, we re-examined the importance of useful energy by postulating a generalized production function with three factors of production, namely capital, labor and useful energy. Effectively, we argue for a macroeconomic theory that fits the facts, not the contrary.

It is difficult to dispute the argument that abundant useful energy at low cost is fundamental to highly industrialized economies like the EU-15. As argued by Nordhaus (1973), energy is an essential input in many economic processes, required by the laws of physics. Although more efficient use might save energy, it simply is not possible to heat houses, produce aluminium, run transportation systems, or generate electricity without it p. 530). Although there are many factors that contribute to economic activity, energy is and always has been important. Effectively, without energy there would be no economies or economics because there would be no goods or services produced or moved from place to place or through markets (Hall and Klitgaard, 2011). 
Many authors (such as Rasche and Tatom (1981); Darby (1982); Hamilton (1983); Gisser and Goodwin (1986); Mork (1989)) argued that changes in the price of energy (particularly oil) has a significant effect on economic activity. Energy shocks could affect economic growth through both supply and demand. On the supply side, we consider the generalized production function of Equation 2. The policy implication here is that the transmission mechanism of energy price shocks on economic growth is through the marginal product of energy. Estimates of the marginal products of useful energy for the EU-15 countries are given in section 5.

Thus, policy makers have a production function that can directly estimate the effects of energy price shocks on economic activity (e.g., $\frac{\partial \mu}{\partial e} \frac{\partial e}{\partial p e}$ where $p e$ is the price of energy relative to the price of output while $\mu$ and $e$ are defined by equation 2). Unlike the argument of neoclassical economists who consider energy as a production factor of only marginal importance at best, we provide strong empirical evidence of the importance of useful energy to support economic activity for the EU-15 countries.

It is important that we clarify this here we discuss the effects of the factor of production and the marginal product of capital, labor and useful energy this is what is usually discussed in the literature. No attempt is made to make claims of the elasticity of substitution between the factors of production. The discussion focused on the direct effects of the factors of production on economic growth without estimating the interaction effects (if any). This is because the empirical estimation of non-linear interaction effects is not trivial while a proper discussion on the properties of the elasticity of substitution or the isoquant merits its own detailed discussion (both from theoretical and empirical macroeconomic perspectives). To jointly and explicitly estimate the marginal products of capital, labor and useful energy and the interaction effects is beyond the scope of the current paper; it would require to extend the generalized production function given of equation 2 .

Overall, we see the following high-level energy-economy policy implications:

- European concern about maintaining working-age population to support retirees is based on the understanding of the importance of labor vis a vis useful energy. The importance of energy in supporting retirees in Europe is underestimated for most EU economies such as Italy, Greece, Denmark, Finland, and UK.

- The need for natural resource taxation (counterbalanced by reduced 
taxation of capital and labor) and the need for robust systems of natural resource governance towards sustainable economic growth trajectories (thinking of energy as an important component of natural resources that drive economic growth).

- Greater availability and productivity of useful energy for mechanical drive and electrical uses (other than lighting and heating). This is because these two categories of useful energy have the highest impact on economic activity as least since 1970s while resource scarcity will elevate resource productivity as an important driver for economic growth.

- Pan-European energy policy whereby cross-border infrastructure projects to support greater movement of energy sources is needed. This is because the current European energy landscape is fragmented (e.g., Western European countries are better placed to cope with energy shocks compared with the Southern European countries).

- Transition to low carbon economic system should be done in a way that ensures both higher accumulation of capital and higher availability and productivity of useful energy. In other words, any investments towards a low carbon system could have positive effects on economic activity by address two of the factors of production. The magnitude of the effect depends on the non-linear relationships presented in section 5 .

- Attention to problems of crude oil resource depletion (particularly the relatively inexpensive crude oil) is important to continuously evaluate any foreseeable collision between increasing consumption of useful energy for mechanical drive (see Figure 2) and the inexpensive crude oil resources of the planet.

Stable full employment and increasing per capita wealth have been economic goals in the EU-15 since at least WW II. Aggregate economic growth has been the principal means for realizing these two goals of full employment and increasing per capita wealth. Over the last few years, the EU-15 has experienced irregular and negative economic growth rates (and significant budget deficits).

Based on our analysis, the EU-15 economic recovery will have to be based on addressing effectively useful energy (on top of the required investments for capital stock and labor inputs) as an important factor of production (at 
least for Greece, Italy, Luxembourg, Finland, Denmark, Sweden and the UK). Our ability to copy with economic contingencies will depend on the ability of our economic growth theory to be sufficiently realistic (in terms of fitting the facts) to permit meaningful links between policy measures and actual growth outcomes. Specifically, the production function of equation 2 answer questions such as is useful energy an important driver of economic activity? And, if so, what is the magnitude of the dependency of economic activity on useful energy?

Towards a new theory of production, our work emphasizes the economic importance of changes in the availability of useful energy flows faced by the EU-15. This is particularly important because it challenges the current economic policy focus of the EU-15 countries on employment. This is not to suggest that employment is unimportant. What we postulate is that policies to enhance the availability and productivity of useful energy (particularly useful energy for mechanical drive and electrical uses) are as important as policies that focus on reforming the labor market. If the EU-15 is to sustain high levels of economic growth as minimum long-run goal, availability of useful energy flows must be developed or there must be unprecedented improvements in useful energy productivity.

We believe that the generalized production function of equation 2 can help us to understand the economic process by giving the actual mechanisms by which that process is occurring.

\section{Acknowledgements}

We would like to thank the four anonymous reviewers for their suggestions and comments. Furthermore, we want to thank the participants of the 2015 CGEP 'Net Energy Analysis' workshop at Stanford University. 


\section{Appendix A: Estimating the generalised production function for the EU-15}

Given the diversity of economic growth of the EU-15 countries and the dynamics of the factors of production, we need to explore the sensitivity of our results to different assumptions with respect to the distribution and factors of production of the proposed generalised production function (see equation 2).

We have estimated the generalised production function using different distribution such as the Gaussian (as a benchmark), gamma (to capture skewness), $t$-family (to capture kurtosis), skewed $t$, Johnson's Su and skew power exponential (to capture both skewness and kurtosis) distributions (see Rigby et al. (2015) for a detailed discussion of the flexibility of different distributions). Thus, we have a used a variate of distributions, including 4parameter skewed-kurtotic distributions. Following Voudouris et al. (2012), the distribution with the lowest Generalized Akaike Information Criterion (GAIC) - as a measure of 'goodness of fit' - suggests the $t$-family distribution as the best conditional distribution to capture the diversity of the EU-15 economic growth dynamics (see figure 1). It is important to emphasise that we are interested in selecting the best possible conditional distribution for the generalised production function of equation 2 (it well be the case that the best marginal distribution might have different properties compared with the best conditional distribution).

In order to explore the sensitivity of our results (of section 5) on alternative distributional assumptions for the generalised production function, figure 18 shows the dynamics of the factors of production for the EU (the sum of the EU-15 countries) for the Gaussian, gamma and $t$-family distributions. It is clear that the results with respect to the key drivers of expected growth

( $\mu$ parameter of equation 2) of the EU-15 are not sensitive to the choice of the distribution for the generalised production function ${ }^{3}$.

\footnotetext{
${ }^{3}$ This might not be the case if a large sample of countries is analysed or when the full predictive density of growth is analysed. The analysis of the predictive density of growth is beyond the scope of the paper.
} 

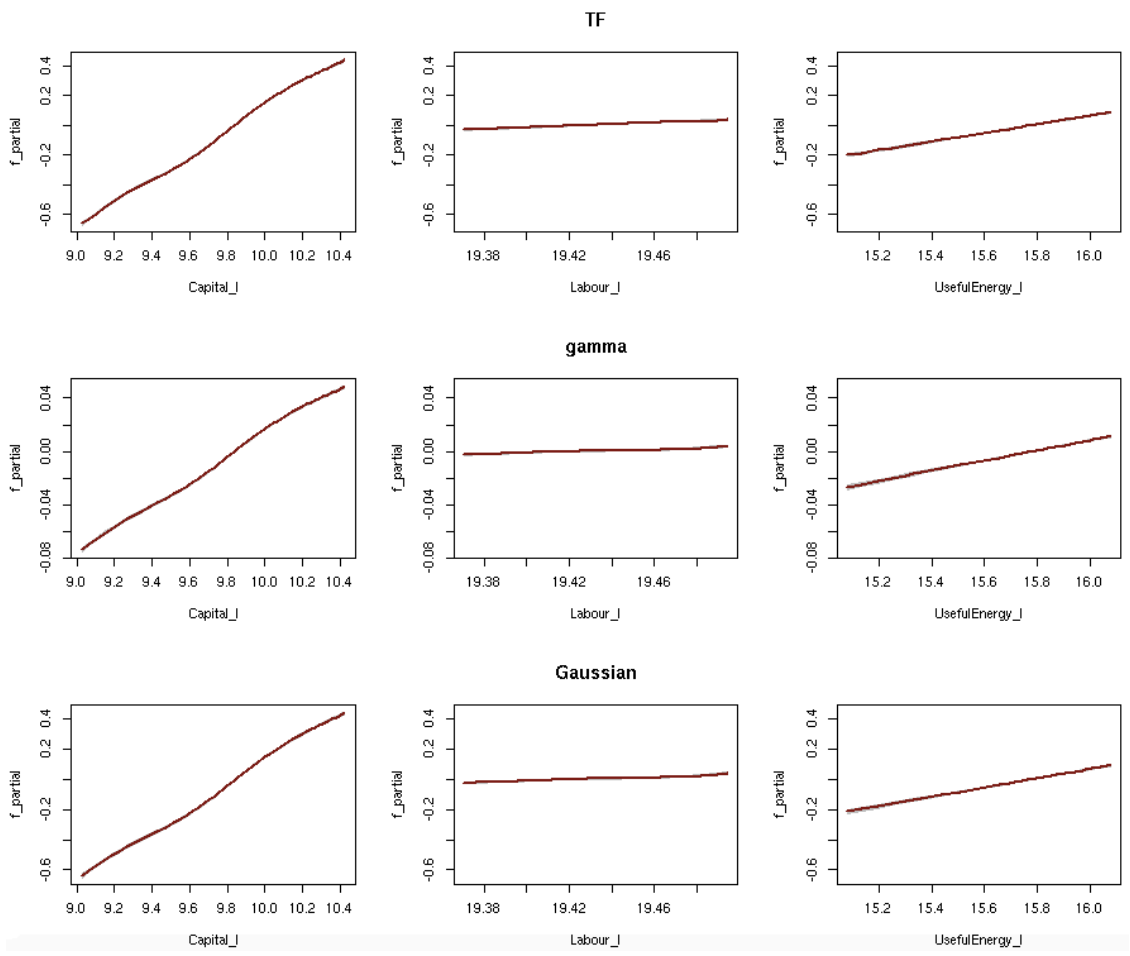

Figure 18: The effect of the factors of production for the $t$ family (TF), gamma and Gaussian distributions.

It is also important to assess how different "combinations" of factors of production might affect the results. Thus, we fit (using the $t$-family distribution) a production function whereby useful energy is decomposed into mechanical drive, lighting, heating, muscle work and other electrical uses. This enables us to determine whether the effects of capital and labor on economic growth have changed dramatically. By comparing Figure 18 and Figure 19, we observe that the dynamics of capital and labor are virtually the same. The results of the effects of capital and labor on economic growth are stable, meaning that their effects do not change based on alternative specifications of the production function. 

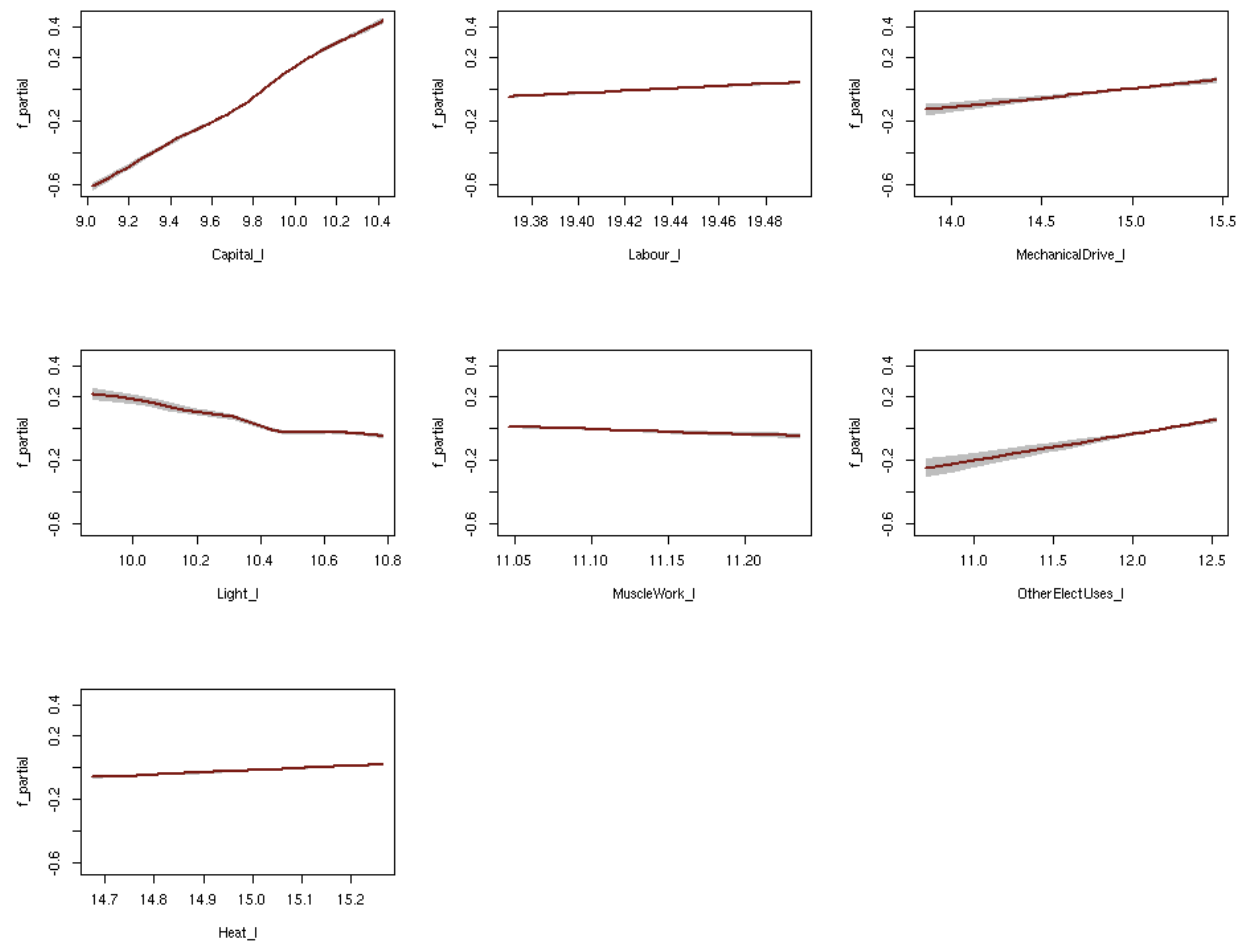

Figure 19: EU - The effects of the detailed factors of production.

Although the aim of the paper is to explore the effects of capital, labor and useful energy on growth, it is interesting to note that mechanical drive and electrical uses are the most important categories of useful energy in terms of supporting the economic growth of the EU-15. The suggestion that not all energy categories are equally important (in terms of supporting economic growth) has important policy implications with respect to the technological innovations needed to support economic growth for the 21st century. For the EU-15 (as an economic block), figure 19 seems to suggest that technological innovations with respect to mechanical drive and electrical uses should be given a policy priority ${ }^{4}$.

\footnotetext{
${ }^{4}$ We aim to explore the effects of the different energy categories on the economic growth of the EU-15 countries in future work.
} 


\section{References}

AMECO (2014). Gross domestic product (income approach), labour costs. http://ec.europa.eu/economy_finance/ameco/user/serie/SelectSerie.cfm.

Ayres, R. and Voudouris, V. (2014). The economic growth enigma: Capital, labour and useful energy? Energy Policy, 64(C):16-28.

Chen, B. and Chen, G. (2007). Modified ecological footprint accounting and analysis based on embodied exergy a case study of the chinese society 19812001. Ecological Economics, 61(23):355 - 376.

Cobb, C. and Douglas, P. (1928). A theory of production. American Economic Review, 18(1):139-165.

Darby, M. (1982). The price of oil and world inflation and recession. American Economic Review, 72(4):738-51.

Ertesvåg, I. S. and Mielnik, M. (2000). Exergy analysis of the norwegian society. Energy, 25(10):957 - 973.

Gisser, M. and Goodwin, T. H. (1986). Crude oil and the macroeconomy: Tests of some popular notions: A note. Journal of Money, Credit and Banking, 18(1):95-103.

Haavelmo, T. (1944). The probability approach to econometrics. Econometrica, 12 .

Haavelmo, T. (1989). Econometrics and the Welfare State. Technical report, Nobel Prize Committee.

Hall, C. and Klitgaard, K. (2011). Energy and the Wealth of Nations: Understanding the Biophysical Economy. SpringerLink : Bücher. Springer.

Hamilton, D. J. (1983). Oil and the Macroeconomy since World War II. Journal of Political Economy, 91(2):228-248.

Harcourt, G. (1972). Some Cambridge Controversies in the Theory of Capital. Modern revivals in economics. Gregg Revivals.

IEA (2014). Energy balances of OECD countries, documentaion for beyond 2020 files. http://dx.doi.org/10.5257/iea/ebnon/2014. 
Johnson, N., Kotz, S., and Balakrishnan, N. (1995). Continuous univariate distributions. Wiley \& Sons.

Klein, L. R. (1946a). Macroeconomics and the theory of rational behavior. Econometrica, 14(2):93-108.

Klein, L. R. (1946b). Remarks on the theory of aggregation. Econometrica, $14(4): 303-312$.

Kümmel, R., Ayres, R. U., and Lindenberger, D. (2010). Thermodynamic laws, economic methods and the productive power of energy. Journal of Non-Equilibrium Thermodynamics, 35(2):145-179.

Leontief, W. (1941). The structure of American economy, 1919-1929: an empirical application of equilibrium analysis. Harvard University Press.

Maddison, A. (1982). Phases of capitalist development. Oxford University Press.

May, K. (1947). Technological change and aggregation. Econometrica, 15(1):51-63.

Mork, K. A. (1989). Oil and the Macroeconomy When Prices Go Up and Down: An Extension of Hamilton's Results. Journal of Political Economy, $97(3): 740-744$.

Nordhaus, W. D. (1973). The Allocation of Energy Resources. Brookings Papers on Economic Activity, 4(3):529-576.

Nordhaus, W. D. (1992). Lethal Model 2: The Limits to Growth Revisited. Brookings Papers on Economic Activity, 23(2):1-60.

Rasche, R. H. and Tatom, J. A. (1981). Energy price shocks, aggregate supply and monetary policy: The theory and the international evidence. Carnegie-Rochester Conference Series on Public Policy, 14(0):9 - 93.

Rigby, R., Stasinopoulos, D., and Voudouris, V. (2015). Flexible statistical models: Methods for the ordering and comparison of theoretical distributions. MPRA Paper No. 63620 (accessed: http://mpra.ub.unimuenchen.de/63620/). 
Rigby, R. and Stasinopoulos, M. (2005). Generalized additive models for location, scale and shape,(with discussion). Appl. Statist, pages 507-554.

Serrenho, A. C., Sousa, T., Warr, B. S., Ayres, R. U., and Domingos, T. (2014). Decomposition of useful work intensity: The EU (european union)15 countries from 1960 to 2009. Energy, 76(C):704-715.

Solow, R. M. (1956). A contribution to the theory of economic growth. Quarterly Journal of Economics, 70(1):65-94.

Solow, R. M. (1957). Technical change and the aggregate production function. The Review of Economics and Statistics, 39(3):312-320.

Total Economy Database (2014). Data. https://www.conferenceboard.org/data/economydatabase/index.cfm?id=27762.

Varoufakis, Y. and Sapsford, D. (1991). Discrete and smooth switching regressions for australian labour productivity growth. Applied Economics, 23(8):1299-1304.

von Thünen, J. (1875). Der isolierte Staat in Beziehung auf Landwirtschaft und Nationalökonomie. Wissenschaftliche Buchgesellschaft.

Voudouris, V., Gilchrist, R., Rigby, R., Sedgwick, J., and Stasinopoulos, D. (2012). Modelling skewness and kurtosis with the BCPE density in GAMLSS. Journal of Applied Statistics, 39(6):1279-1293.

Wall, G., Sciubba, E., and Naso, V. (1994). Exergy use in the italian society. Energy, 19(12):1267 - 1274.

Wood, S. (2006). Generalized Additive Models: An Introduction with $R$. Taylor \& Francis. 